\title{
The Effectiveness of Core Muscle Exercises on the Muscle Strength \\ Level and Some of the Biomechanical Variables Associated with the Jump Shooting Skill Performance in Handball
}

\author{
*Asst. Prof. Dr. Ranya Mohamed Saeed Mahmoud
}

\author{
Assistant Professor, Department of Training of Physical Sports, Faculty of \\ Physical Education for Girls in Cairo - Helwan University - Egypt.
}

\begin{abstract}
:
This research aims to identify the effectiveness of core muscle Exercises on the muscle strength level (legs, trunk, and arms) and the performance level of the jump shooting skill for female handball players, as well as some biomechanical variables associated with the skill performance (performance stages time distribution, the body's movement course horizontal displacement value, the shooting hand movement horizontal displacement value, the body's gravity center height on the vertical axis at the elevation moment value, the elevated foot at the body launch moment vertical velocity components value, the shooting arm at the ball release moment horizontal velocity components value, the fixed shooting leg, the free leg, and the elevated foot joints angular change value, some body positions and parts angular change values percentages). The researcher used the descriptive approach through biomechanical analysis of the jump shooting skill, and the experimental method of one-group design on a sample of (7) female national players in the Helwan University team for handball, who performed (3) shooting attempts, before and after the application of core muscle Exercises. and the researcher used strength and muscle ability tests, and skill level tests for the jump shot skill. The Exercises program consisted of (30) units for (10) weeks period, with (3) Training units per week, and a capacity of (60) minutes per unit. The results showed improvement in the biomechanical variables (under study), strength and muscle ability measurements (legs, trunk, and arms) and the jump shooting skill performance of the research sample players.
\end{abstract}

\section{Research Terminologies:}

Core muscles, core stability, biochemical variables, jump shooting.

\section{Introduction and Research Problem:}

Bliss (2005), Dave Schmitz (2003), and Ron Jones (2003) suggest that corebody strengthening exercises have become the main key to athletes Exercises programs for all levels. It acts as a bridge that connects the upper and lower extremities, in addition to preventing force leakage, and the force resulted from the core body part is called the extremities power source.

Core body part term refers to the trunk and pelvis area, which includes the abdominal muscles (rectus, transverses, internal, external, and oblique's), the hip muscles (front, back), and the spinal muscles (Lower back muscles, and upper back muscles); these groups are connected to the legs, shoulders, and arms muscles. (Greg, B, 2003, Dean, B) It consists of (29) muscles and is located in the center of gravity of the body when the movement begins. (Prentice: 2003) 
Akuthota, and Nadler (2004) add that the core muscles work on the complete transfer of the force produced from the lower extremity through the trunk to the upper extremity and sometimes the held tool. Therefore, the core muscles weakness will not lead to a complete motor energy transfer from the lower to upper and thus poor athletic performance.

The trunk has an important effect on the shooting skill performance in handball, for when the player starts preparing for the swing, following that the torso rotates backward inverting the throwing direction until the shoulder axis crosses the pelvic axis and the left shoulder faces the goal in order to achieve the foothold of the left leg for the right player. When the trunk completes its swing, this moment is considered to be the starting moment to turn facing the direction of shooting, by transferring the movement from the trunk to the shooting arm, where the shoulders axis rotates to face the goal through the forward movement of the arm and the trunk forward rotation, followed by the whip movement of the forearm and wrist. The strength and accuracy of the shot depends on the trunk strong rotation the foothold movement on the front left foot and the arm's whip movement. (Reita, E, Mary P: 1997)

Amal Gaber (2008), Adel Abd El Basir, Ehab Adel (2007), and Laila El Sayed Farhat (2005) agree that the kinetic analysis is done with the aim of identifying the skill technical characteristics, revealing performance defects and comparing it with theoretical curves. Also the theoretical study of the sample movement and their kinetic possibilities, and the evaluation through biomechanical kinematic analysis is done through studying the skill motor course mechanical variables. This is done according to the mathematical movement laws and the resulting variables that affect motor performance, and it is the best method of objective evaluating.

Through the researcher's viewing of scientific references and Arab and foreign studies, she found lack of quality research that is concerned with linking the biomechanics fields as a scientific field and activating it to study skill performance problems in handball. This prompted the researcher to connect between the core muscle strength development as one of the most important physical components affecting the implementation of the kinematic duties of the jump shot skill, and between one of the biomechanics modern sciences and its applications in sports activity.

The jump shooting skill is a complex motor skill that requires an accurate neuromuscular compatibility of the feet, trunk and the shooting arm movement during correct skill performance. Due to the presence of some deficiencies in the interest of specialized Exercises that focuses on the physical components development of the jump shooting skill, the idea of this research occurred as an attempt to link the core muscle strength development with the long jump shooting skill biomechanical variables. Therefore, the research problem was shaped in identifying the developing core muscle strength effect on the quantitative values of some biomechanical variables for jump shooting skill, through diagnosing the handball female players' skill performance. 


\section{Research Objectives:}

The research aims to identify:

1. Biomechanical analysis of the jump shooting for handball female players.

2. Designing a group of core muscle exercises, and identifying their effect on:

a) Some biomechanical variables affecting the jump shot skill performance (performance stages time distribution, the body's movement course horizontal displacement value, the shooting hand movement horizontal displacement value, the body's gravity center height on the vertical axis at the elevation moment value, the elevated foot at the body launch moment vertical velocity components value, the shooting arm at the ball release moment horizontal velocity components value, the fixed shooting leg, the free leg, and the elevated foot joints angular change value, some body positions and parts angular change values percentages).

b) The muscle strength level (legs, trunk, and arms), as well as the jump shooting performance skill of handball female players.

\section{Research Hypothesis}

1. There are statistically significant differences between the pre and post measurements in some biomechanical variables values that affect the long jump shooting skill performance of the research sample handball female players in favor of the post measurement.

2. There are statistically significant differences between the pre and post measurements in the muscle strength level (legs, trunk, arms), as well as the jump shooting skill level of the research sample handball female players in favor of the post measurement.

\section{Research Plan and Procedures}

\section{Research Methodology}

The researcher used the descriptive method through biomechanical analysis of the jump shooting skill for handball female players, as well as the experimental method of one experimental group using the pre and post measurement to apply the proposed core strength Exercises, and to determine the biomechanical changes to measure the development of the core muscle strength effect of handball female players.

\section{Research Community}

The research community contained (27) national handball team female players in Helwan University, all of whom are registered in the Egyptian Handball Federation for the sports season (2019-2020).

\section{Research Sample}

The research sample was chosen by the intentional method from national handball team female players in Helwan University, who are students of in the 
Faculty of Physical Education for Girls in El Gezira, and their number is (7) players. Each player performed ( 3 attempts) to jump shot before and after the application of core muscle exercises Each player performed ( 3 attempts) of the jump shot before and after the application of core muscle exercises, and the best attempts of each player were chosen for the purpose of biomechanical kinematic analysis, the number of attempts under study became (14 attempts); 7 attempts before and 7 attempts after applying core muscle Exercises. Additional (20 players) were selected to conduct the pilot study, and calculate the scientific treatments for the physical and skill tests under study.

\section{Research Sample Homogeneity:}

Table (1)

Arithmetic mean, Standard deviation, and Torsion coefficient of the variables understudy - pre-measurements $(n=7)$

\begin{tabular}{|c|c|c|c|c|c|}
\hline & Variables & $\begin{array}{c}\text { Measurement } \\
\text { Unit }\end{array}$ & Mean & SD & $\begin{array}{c}\text { Torsion } \\
\text { coefficient }\end{array}$ \\
\hline \multirow{4}{*}{ 旁 } & Age & Year & 20,15 & 1,17 & $\mathbf{0 , 2 3}$ \\
\hline & Height & Meter & 171,8 & $\mathbf{0 , 6 3}$ & 0,132 \\
\hline & Weight & Kg & 65 & 1,41 & $-2,10$ \\
\hline & Exercises age & Year & 12,3 & $\mathbf{0 , 0 2}$ & 1,83 \\
\hline \multirow{12}{*}{ 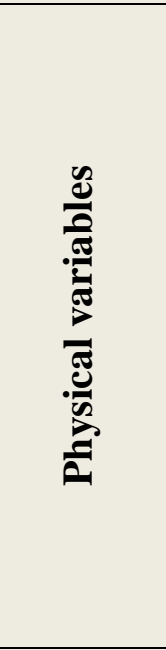 } & Legs strength in dynamometer & Kg & 68,00 & 14,49 & $\mathbf{0}$ \\
\hline & Back strength in dynamometer & Kg & 64,28 & 12,39 & $-0,17$ \\
\hline & Sit ups & Repeat & 21,57 & 4,03 & 1,17 \\
\hline & Push ups & Repeat & 18,57 & 3,10 & $-0,41$ \\
\hline & Standing broad jump & $\mathrm{Cm}$ & 148 & $\mathbf{8 , 5 2}$ & $\mathbf{1 , 0 5}$ \\
\hline & Broad jump (3 steps) & $\mathbf{C m}$ & 176,28 & 24,34 & $\mathbf{0 , 2 8}$ \\
\hline & Vertical jump with swing arms & $\mathbf{C m}$ & 22,57 & 4,96 & $-0,864$ \\
\hline & Vertical jump without swing arms & $\mathbf{C m}$ & 18,57 & 2,29 & 0,74 \\
\hline & Medicine ball trunk rotation throw & Meter & $\mathbf{5 , 3 5}$ & $\mathbf{0 , 7 8}$ & $-2,10$ \\
\hline & Medicine ball trunk rotation $(30 \mathrm{sec})$ & Repeat & 19,57 & 1,81 & $\mathbf{0 , 9 4}$ \\
\hline & $\begin{array}{l}\text { Throwing medicine ball to farthest } \\
\text { point }\end{array}$ & Meter & 7,19 & 1,45 & 1,01 \\
\hline & Strength\& stability of core muscles & Grade & 41,25 & $\mathbf{0 , 9 8}$ & $\mathbf{0 , 5 1}$ \\
\hline \multirow{2}{*}{ 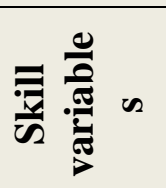 } & $\begin{array}{c}\text { Long jump shot\& calculating fly } \\
\text { distance }\end{array}$ & $\mathbf{C m}$ & 188,10 & $\mathbf{0 , 2 7}$ & $-1,37$ \\
\hline & $\begin{array}{l}\text { Long jump shot accuracy on goal } \\
\text { corners }\end{array}$ & Grade & 47,79 & $\mathbf{9 , 1 7}$ & $-1,22$ \\
\hline
\end{tabular}

\section{Data Collecting Tools}

1. Arab and foreign reference sources, previous studies, and the International Information Network:

In order to identify the biomechanical variables, the physical tests, and the skill tests of the jump shooting skill, and how to conduct the study. (Talha H. 2006) (Adel A., Ehab A. 2007) (Fathy A. 2010) (Kamal D.2002) , (Kamal A., Mohamed, S., 2010) (Mohamed K., 2004) (Mohamed S.,: 2006) (Melvin, R: 2003). 
2. An expert opinion survey form to determine: Physical and skill tests, as well as determining the general framework for implementing the proposed exercises in terms of duration - Training unit's number - Training unit time - core muscle exercises

3. The Tests used in the Research:

a) Physical Tests:

- Muscle Strength Tests:

- Legs strength in dynamometer (Mohamed, S., 2001)

- Back strength in dynamometer (Mohamed, S., 2001)

- Abdomen muscle strength (Sit ups $20 \mathrm{sec}$ ) (Mohamed, S., 2001)

- Arms muscle strength (Push-ups) (Mohamed, S., 2001)

- Leg muscles strength and ability tests in the horizontal and vertical directions

- Standing broad jump. (Kamal A., Mohamed S. 2010)

- Broad jump (3 steps) and elevating with one leg, it is similar to the jump shooting skill understudy. (Researcher Design)

- Vertical jump with swing arms. (Kamal A., Mohamed S. 2010)

- Vertical jump without swing arms with the purpose of identifying the effect of the swinging arms amount result on vertical jump. (Kamal D. 2002)

- Trunk and arms muscles strength and ability tests

- Medicine ball trunk rotations throw. (Researcher design)

- Medicine ball trunk rotation (30 sec). (Researcher design)

- Throwing medicine ball to farthest point. (Kamal D. 2002)

- Core muscles strength and stability test to measure the body's core part strength.

- (Aishe,E:2011)( www.w3c.org/TR/1999).

b) Skill Tests:

- $\quad$ Long jump shot\& calculating fly distance. (Kamal D. 2002)

- Long jump shot accuracy on goal corners. (Researcher design)

\section{Tools and Devices:}

a) Photographing devices and tools for kinematic analysis purpose:

- (Canon EOS-1DC) camera with a resolution of (18.1 Megapixels)

$(24 \mathrm{~mm}$ X36 mm) (Pixels $5184 \times 3456)$ with a frequency of $(100)$ images per second was used.

- Camera Tripod Stand.

- Memory Card, Flash memory (32 GB) to plug to the computer.

- Wooden ruler $(3 \mathrm{~m})$ to calculate the scale.

- Computer Device.

- Movie Maker Windows program to edit videos, and Any Video Converter to convert video extension to AVI.

b) Tools for measurements, tests and suggested core muscle exercises:

Rastameter to measure height, medical scale to measure weight, dynamometer to measure the back and leg muscles strength, tape measure, stop watch, medicine balls, hand balls, chalk, collars, Swiss ball, Swiss hemisphere ball, hand wheel, Roman seat, Boules balls.

\section{Research Implementation Procedures:}




\section{First Pilot Study:}

The researcher conducted the first pilot study on (20) players from the research sample original community, and they are not enrolled in the research sample, from Monday 2/9/2019 to Monday 9/9/2019 in order to ensure:

- Devices and tools used validity.

- The possibility of implementing and applying measurements and tests and its related procedures according to the established conditions.

- Assistants Exercises on implementing measurements and tests.

- Calculating the scientific treatments of the tests under study.

Tests Scientific Treatments: First Tests Validity:

Table (2)

The significance differences between the significant and insignificant groups in the physical and skill variables under study $(\mathrm{n} 1=\mathrm{n} 2=10)$

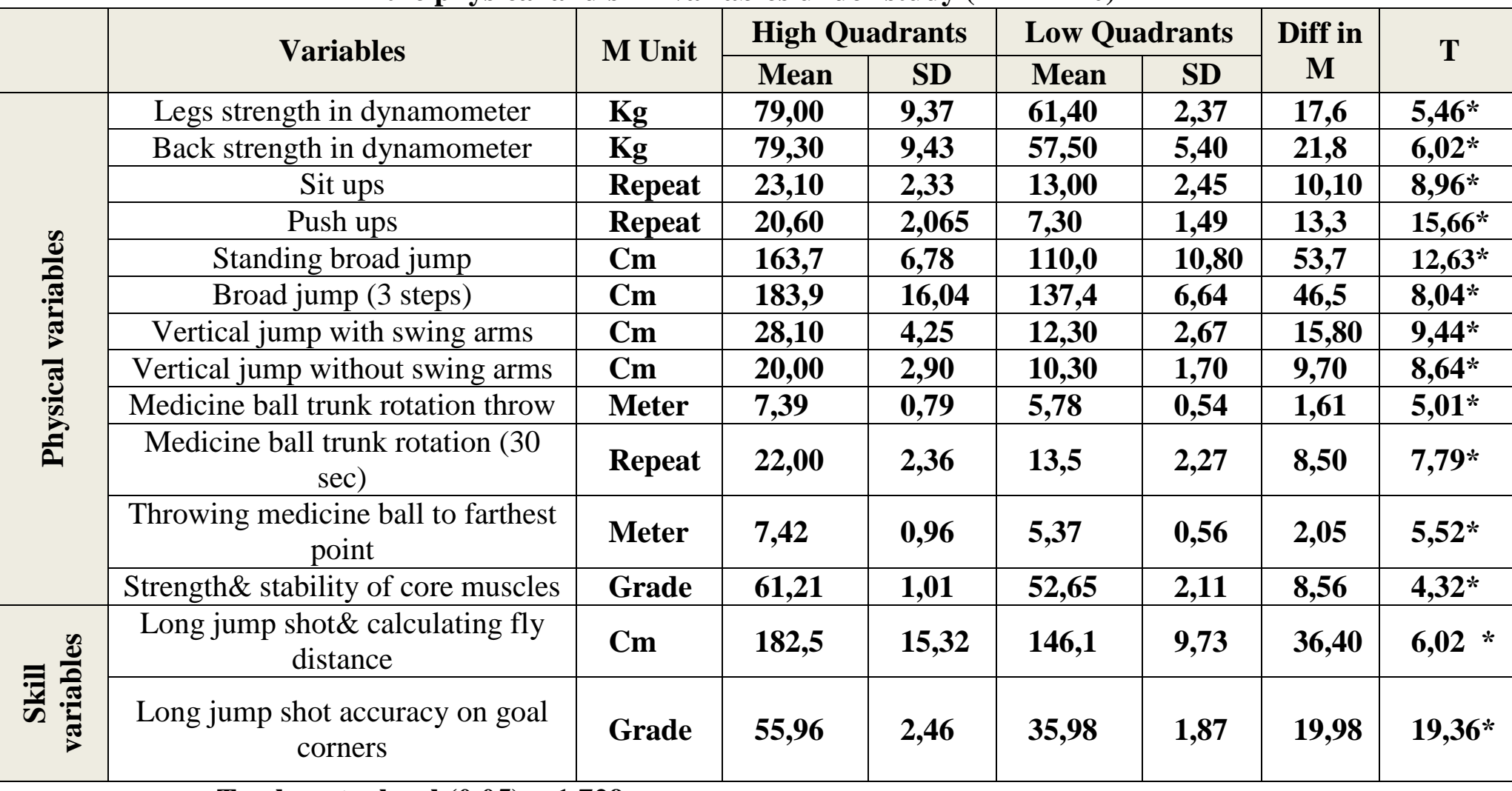

T value at a level $(0.05)=1,729$

Second Tests Stability

To verify the test stability, the researcher used the test applying method and re-applying it to the pilot sample, and used the test validity account data as the first application on Monday 2/9/2019 and the second application a week after the first application on Monday 9/9/2019. 
Table (3)

Correlation coefficient between the first and second applications in the physical and skill variables under study $(n=20)$

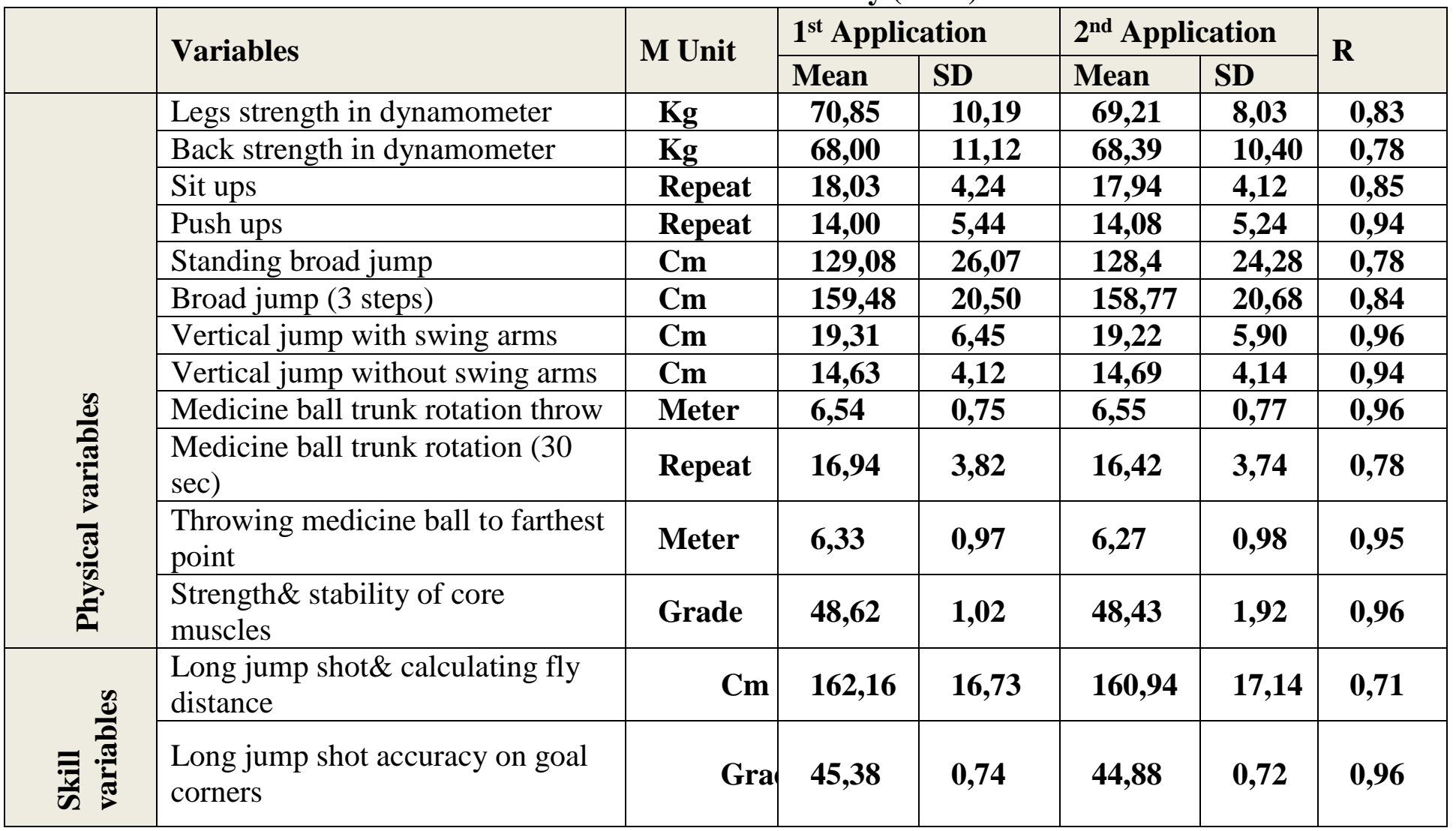

$R$ value at a level $(0.05)=0,43$

\section{Second Pilot Study}

The researcher conducted the second pilot study on (5) female players from the research community and outside the main research sample on Sunday 15/9/2019 in the handball court at Faculty of Physical Education for Girls in El Gezira, in order to prepare the filming location as follows:

- Determining the camera position location for analytical photography purpose, as the camera position was set at a distance $(10 \mathrm{~m})$ from the player's foothold and at a height of $(1.20 \mathrm{~m})$ from the ground, and the camera angle was placed so that it is perpendicular to the player's side during the performance.

- $\quad$ Set the most appropriate timing for filming the video.

- Set the camera position according to the sun movement.

- Determine the player's field motion during the skill performance to determine the sector of viewing during filming.

- Availability of an electrical source near the camera.

- Determine control marks location for the scale.

- Identify the obstacles the researcher faces during the filming process and try to overcome them, including the tripod stability on the ground, its height relative to the players, and the availability of photography aids. 


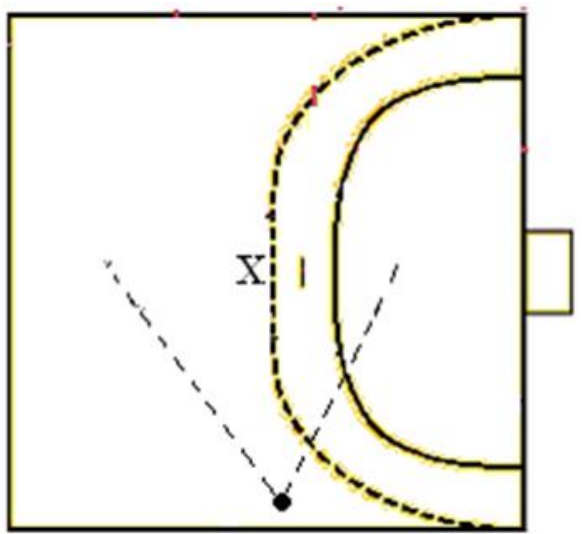

Figure (1) Camera position [*] Camera, [X] shooting player Proposed Core Muscle Exercises Program:

The proposed core muscle Exercises program aims to develop the body's core part muscles strength, and to improve the legs, arms, and trunk muscular ability to raise jump shooting skill level of the research sample female handball players by improving the skill some biomechanical variables.

\section{Proposed Program Setting Foundations}

- The exercises were developed in light of the jump shooting skill technical standards, which serve the skill's motor stages.

- Setting exercises in the light of muscular work for skill performance stages.

- Safety and security factor availability for the Exercises place and the tools used.

- Provide the necessary tools and devices to implement the program.

- Taking into account the individual differences between the research sample players.

- Pay attention to warm-up and prepare the body for Exercises.

- Gradient from easy to difficult, from simple to complex, and from stillness to movement.

\section{Program Time Division}

The program was divided into (30) training units for a period of (10) weeks, at the rate of (3) Training units per week, with a time of (60) minutes per unit, according to the experts opinion.

\section{Forming Exercises Endurance:}

The researcher gradated in the endurance intensity from medium to maximum intensity, where she divided the total endurance cycle into (10) weeks, and each week into (3) Training units, where the endurance gradate were distributed among the Exercises weeks during the Exercises program stages, to start from 55\% to 90\%. The principle of gradual increase in the endurance intensity and size during the Exercises program stages according to the objectives was in consideration, as it started from 55$65 \%$ to $75-90 \%$ of the maximum that an individual can endure.

The researcher legalized the Exercises endurance by determining the appropriate dose for each exercise by dividing the maximum number of repetitions by (2) and recording the time spent by the player in performing each exercise and its endurance, as well as recording the rest time between each exercise and the one after.

\section{Exercises Method}

The researcher used the low-intensity interval Exercises method in the program implementation first stage, and high-intensity interval Exercises in the 
second and third stages.

\section{Proposed Program Design}

The program was divided into (3) stages:

First stage:

- Stage content: initial exercises for the body's core part stability by performing the exercises in a steady position.

- Endurance intensity: 55\% - 65\%

- Duration of the stage: (2) weeks.

- Number of units: (6) units.

Second stage:

- Stage content: complex exercises to stabilize body's core part by performing exercises in a steady position with the arms and legs movement.

- Endurance intensity: 65\% - 80\%

- Duration of the stage: (4) weeks.

- Number of units: (12) units.

Third stage:

- Stage content: Initial and complex exercises and performing exercises in steady and moving position.

- Endurance intensity: $80 \%-90 \%$

- Duration of the stage: (4) weeks.

- Number of units: (12) units.

\section{Training unit Components}

a) The preparatory part (warm-up and stretching): This part achieves general preparation and stretching for all body muscles; it includes running, partridge, jumping and joint flexibility exercises. The warm-up time is (15min) from the Training unit total time.

b) The main part: This part achieves the programs' main goal and includes the proposed core muscle exercises. This part is (40 min) from Training unit total time.

c) The final part (cooling down): This part achieves the players returning to normal state through light running and cooling exercises. This part is (5 min) from the Training unit total time.

\section{Third Pilot Study}

The researcher conducted the third pilot study on (9) female players from the research community outside the main research sample on Wednesday 18/9/2019 in the handball court at Faculty of Physical Education for Girls in El Gezira, in order to test a Training unit from the program, and the study resulted in:

- Exercises suitability with the training unit time.

- Suitable exercises that fits the player's level.

- Being able to determine the actual performance time for each exercise, the average number of repetitions, and the average time between groups.

Table (4) shows a unit model for the proposed program units. 
Table (4)

The proposed program training unit model

Second week, fifth unit, training Level: (foundation) Unit time: $60 \mathrm{~min}$.

\begin{tabular}{|c|c|c|c|c|c|c|}
\hline Unit Parts & Duration & Content & Intensity & Repeat & Groups & $\begin{array}{c}\text { Rest between } \\
\text { groups }\end{array}$ \\
\hline Warm Up & 15 mins & $\begin{array}{l}\text { - Run around the handball court } \\
\text { - (Standing) jumping with feet in place } \\
\text { - (Standing) jumping with feet in place, } \\
\text { forth and back } \\
\text { - (Standing) jumping with the feet in } \\
\text { place to the right and left } \\
\text { - (Standing) jump open, join legs in } \\
\text { place } \\
\text { - Stretching exercises for the legs, trunk } \\
\text { and arms muscles }\end{array}$ & & & & \\
\hline Main Part & 40 mins & $\begin{array}{l}\text {-Push-ups (stability) } \\
\text { - Bridge Marching } \\
\text { - Sit up with leg raises } \\
\text { - Superman Exercise }\end{array}$ & $\begin{array}{c}\% 55 \\
- \\
\% 65\end{array}$ & 20 & 6 & $45 \mathrm{sec}$ \\
\hline Final Part & 5 mins & - Jogging, stretching, and breathing & & & & \\
\hline
\end{tabular}

Main Study

Pre Measurements:

Pre measurements were conducted on the variables under study according to the following order:

- Saturday 21/9/2019, measuring the research sample physical and skill tests.

- Sunday 22/9/2019 filming the jump shooting skill for the research sample of (7) female players, where each player performed (3) shooting attempts and each player best attempt was chosen based on the criteria of correct jump shooting technical performance to extract the biomechanical variables in the skill performance technical stages.

\section{Program Application}

The proposed core muscle training program was applied on the research sample over a period of (10) weeks, (3) training units per week on (Saturday, Monday, and Wednesday), and (30) training units with a capacity of (60) minutes, in the period from Monday 23/9/2019 to Monday 2/12/2019 in the handball court at Faculty of Physical Education for Girls in El Gezira.

\section{Post Measurements}

The post measurements were conducted after the proposed program implementation completion on the research sample, with the same sequence and conditions followed in the pre-measurements.

- Wednesday 4/12/2019 measuring the research sample physical and skill tests.

- Thursday 5/12/2019 filming the jump shooting skill to extract the biomechanical variables extracted in the pre-measurement.

\section{Statistical Treatments}

The researcher used the following statistical treatments:

- Arithmetic mean. 
- Median.

- Standard Deviation.

- Torsion coefficient.

- T-Test.

- Correlation coefficient Pearson.

- Improving Percentage.

- Significance differences test for small samples (parametric) using SPSS software.

- $\left(\mathrm{Q}^{2}\right)$

Results Presentation and Discussion

First: The research sample jump shoot performance most important biomechanical characteristics presentation and discussion:

1) Jump shooting skill performance stages time distribution (preparatory stage - main stage - final stage) for the research sample female players.

Table (5)

Jump shooting performance stages time distribution statistical description for the research sample female players $(n=7)$

\begin{tabular}{|c|c|c|c|c|c|c|c|}
\hline Measurement & $\begin{array}{c}\text { Performance } \\
\text { stages }\end{array}$ & $\begin{array}{c}\text { Measure } \\
\text { unit }\end{array}$ & Mean & SD & Minimum & Maximum & Range \\
\hline \multirow{6}{*}{ Pre } & Preparatory & Sec & $\mathbf{0 , 2 1 1}$ & $\mathbf{0 , 1 9 5}$ & $\mathbf{0 , 2 0}$ & $\mathbf{0 , 2 4}$ & $\mathbf{0 , 0 4}$ \\
\cline { 2 - 8 } & Main & Sec & $\mathbf{0 , 1 5 3}$ & $\mathbf{0 , 0 5 5}$ & $\mathbf{0 , 1 2}$ & $\mathbf{0 , 2 7}$ & $\mathbf{0 , 1 5}$ \\
\cline { 2 - 8 } & Follow-up & Sec & $\mathbf{0 , 0 8}$ & $\mathbf{0 , 0 0 0}$ & $\mathbf{0 , 0 8}$ & $\mathbf{0 , 0 8}$ & $\mathbf{0 , 0 0}$ \\
\hline \multirow{3}{*}{ Post } & Preparatory & Sec & $\mathbf{0 , 2 1 1}$ & $\mathbf{0 , 1 9 5}$ & $\mathbf{0 , 2 0}$ & $\mathbf{0 , 2 4}$ & $\mathbf{0 , 0 4}$ \\
\cline { 2 - 8 } & Main & Sec & $\mathbf{0 , 1 2 0}$ & $\mathbf{0 , 0 0 0}$ & $\mathbf{0 , 1 2}$ & $\mathbf{0 , 1 2}$ & $\mathbf{0 , 0 8}$ \\
\cline { 2 - 8 } & Follow-up & Sec & $\mathbf{0 , 0 8}$ & $\mathbf{0 , 0 0 0}$ & $\mathbf{0 , 0 8}$ & $\mathbf{0 , 0 8}$ & $\mathbf{0 , 0 0}$ \\
\hline
\end{tabular}

Table (6)

The significance differences between the jump shooting skill stages time distribution in both the pre and post measurements for the research sample

female players $(n=7)$

\begin{tabular}{|c|c|c|c|c|c|c|}
\hline Measurement & Groups & Groups no. & $\begin{array}{l}\text { Average } \\
\text { Range }\end{array}$ & $\mathbf{X}$ & $\begin{array}{c}\text { Freedom } \\
\text { Level }\end{array}$ & $\begin{array}{c}\text { Significance } \\
\text { diff. }\end{array}$ \\
\hline \multirow{3}{*}{ Pre } & 1 & 7 & 17,00 & \multirow{6}{*}{16,584} & \multirow{6}{*}{2} & \multirow{6}{*}{$* * * 0,000$} \\
\hline & 2 & 7 & 12,00 & & & \\
\hline & 3 & 7 & 4,00 & & & \\
\hline \multirow{3}{*}{ Post } & 1 & 7 & 18,00 & & & \\
\hline & 2 & 7 & 11,00 & & & \\
\hline & 3 & 7 & 4,00 & & & \\
\hline
\end{tabular}

Group 1=preparatory level Group 2= main level Group 3= final level

In light of the results presented in tables (5) and (6), the researcher can infer some phenomena related to performance characteristics, including:

1. The preparatory movement performance time arithmetic mean (approach steps, shooting arm preparatory swing, elevation and foot instep touching the ground) reached $(0.211 \mathrm{sec})$ and represents $(50 \%)$ of the skill total performance time, evenly for pre or post measurement. The researcher sees that the preparatory stage took a longer time than the main and follow-up stages due to its importance, as it aims to prepare for the basic movement by gathering forces and increasing speed through the shooting arm approaching 
steps and the preparatory movement invert the throwing direction and bending the elevating leg joint, which leads to the appropriate stretching of the working muscles preparing for the appropriate muscle contraction to perform the basic movement. This is in agreement with what "Amal Gaber Berekaa" (2008), "Adel Abd El Basir and Ehab Adel Abd El Basir" (2007), and "Mounir Gerges" (2004) indicated that the preparatory stage aims to well prepare for the main stage, which accomplish the basic mechanical goal, which is obtain a horizontal distance towards the goal to reach the nearest shooting point. The preparatory stage serves the main part and works to prepare the movement performance necessary strength. It is an important stage from a mechanical point of view because it is responsible for placing the shooting arm at the most appropriate point to start the basic movement in the goal direction.

2. The body's basic movement performance time (fly) and shooting arm basic movement in the shooting direction until the ball launches and releases (fly) reached $(0,153 \mathrm{sec})$ from the skill total performance time in the premeasurement, and $(0.120 \mathrm{sec})$ at a rate of $(30 \%)$ from the skill total performance time in post measurements. The researcher sees that this stage is during which the basic movement mechanical goal is achieved and the force obtained in the preparatory stage are exploited, as it represents (the effect and result) while the preparatory stage represents the cause.

3. The skill performance time final part (follow-up) reached $(0.08 \mathrm{~s})$, which was represented in the landing process to the surface from the body's flying state and restoring balance and it represents $(20 \%)$ of the skill performance total, evenly in the pre or post measurement. As the correct landing on the elevated foot followed by the other foot helped maintain the balance quickly after shooting and in a shorter period of time than the previous two stages. After the ball is launched and the player reaches the maximum height, the landing takes place by the action of gravity, where follow up importance is summarized in absorbing the performance redundant energy and making the body maintain its balance. (www.iraqacad.org)

4. There is a variation in the time distribution values, whether in the skill performance total time or the three stages time of the skill performance requirements (preparatory- main - follow-up) for most of the research sample female players between the pre and post measurements. In general, the average of shooting ball basic movement performance improved, as the basic stage average time improved from $(0.153 \mathrm{sec})$ for pre-measurement to $(0.120 \mathrm{sec})$ for post-measurement.

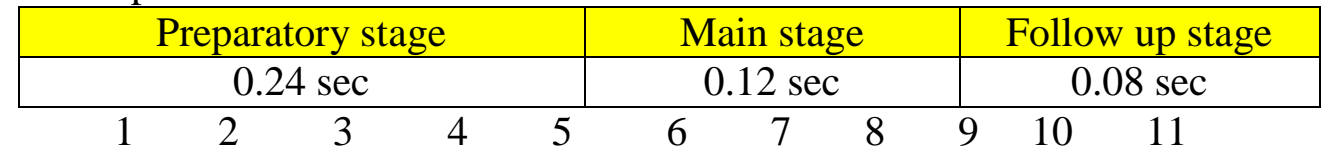

Figure (2) linear chronogram for the jump shot performance stages time distribution of the research sample

2) The horizontal displacement value of the body's motion path during the jump shot skill performance 
Table (7)

The body's movement path from the gravity center horizontal displacement $(\mathrm{cm})$ during the jump shooting skill performance in (pre/post) measurements of the

\section{research sample}

\begin{tabular}{|c|c|c|c|c|c|c|c|c|c|c|c|c|c|c|c|}
\hline \multirow[t]{2}{*}{ Statement } & \multirow{2}{*}{$\begin{array}{c}\text { Measure } \\
\text { unit }\end{array}$} & \multicolumn{2}{|c|}{ Player 1} & \multicolumn{2}{|c|}{ Player 2} & \multicolumn{2}{|c|}{ Player 3} & \multicolumn{2}{|c|}{ Player 4} & \multicolumn{2}{|c|}{ Player 5} & \multicolumn{2}{|c|}{ Player 6} & \multicolumn{2}{|c|}{ Player 7} \\
\hline & & Pre & Post & Pre & Post & Pre & Post & pre & Post & Pre & Post & Pre & Post & Pre & Post \\
\hline 0,04 & sec & 53 & 55 & 52 & 43 & 38 & 35 & 43 & 45 & 50 & 54 & 36 & 43 & 43 & 45 \\
\hline 0,08 & sec & 55 & 52 & 55 & 52 & 43 & 43 & 52 & 53 & 43 & 50 & 43 & 52 & 52 & 53 \\
\hline 0,12 & sec & 52 & 38 & 33 & 29 & 38 & 32 & 38 & 34 & 35 & 38 & 33 & 31 & 38 & 36 \\
\hline 0,16 & sec & 55 & 54 & 38 & 45 & 40 & 50 & 43 & 47 & 45 & 52 & 36 & 45 & 52 & 55 \\
\hline 0,2 & sec & 60 & 57 & 43 & 55 & 43 & 57 & 52 & 55 & 54 & 55 & 45 & 55 & 50 & 60 \\
\hline 0,24 & sec & 65 & 62 & 50 & 62 & 54 & 65 & 55 & 60 & 60 & 65 & 55 & 62 & 57 & 65 \\
\hline 0,28 & sec & 60 & 57 & 45 & 54 & 43 & 56 & 52 & 55 & 55 & 54 & 45 & 45 & 50 & 62 \\
\hline 0,32 & sec & 54 & 55 & 38 & 45 & 38 & 52 & 43 & 45 & 43 & 52 & 38 & 45 & 53 & 55 \\
\hline 0,36 & sec & 52 & 36 & 33 & 31 & 31 & 29 & 34 & 36 & 39 & 40 & 33 & 34 & 36 & 36 \\
\hline
\end{tabular}

Table (7) shows the horizontal displacement value change of the body's movement path during the jump shooting skill performance in the two measurements (pre- post), and the shaded part in the table shows the body's position at the moment the elevating foot is released to start the player's body flight, until the end of the flight and the beginning of the landing point.

In light of the results presented in the previous table, the researcher can discuss these results as follows:

1. The horizontal displacement values of the body's path movement in samples pre and post measurements were variable from the movement beginning to its end as a result of the gradual increase in the gravity center height, especially with the body's flight beginning.

2. The player's pre and post measurements highest value came at a time $(0.24$ sec), and the researcher sees that this value reflects the moment when the player is at the maximum height while performing the skill basic movement and also the shooting arm basic movement, which is the decisive moment in determining the appropriate angle to shot the ball.

3. The reduction in the horizontal displacement value in the post measurement over the pre-measurement at the elevating foot release moment in $(0.16 \mathrm{sec})$ time for some players is attributed by the researcher to the elevating foot pushing force the increase, that is presented in is the body's launch into the air starting force; Which could be a result of the core muscle exercises under study.

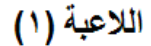

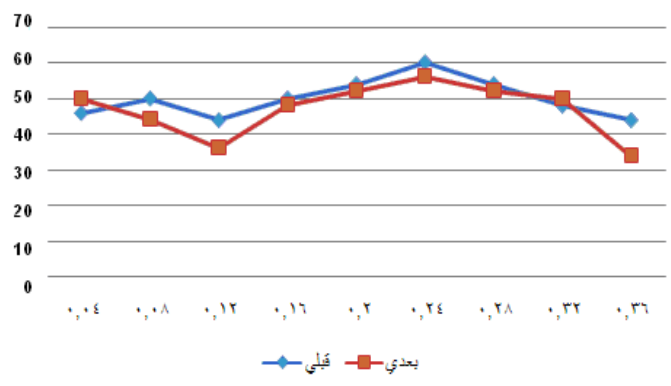



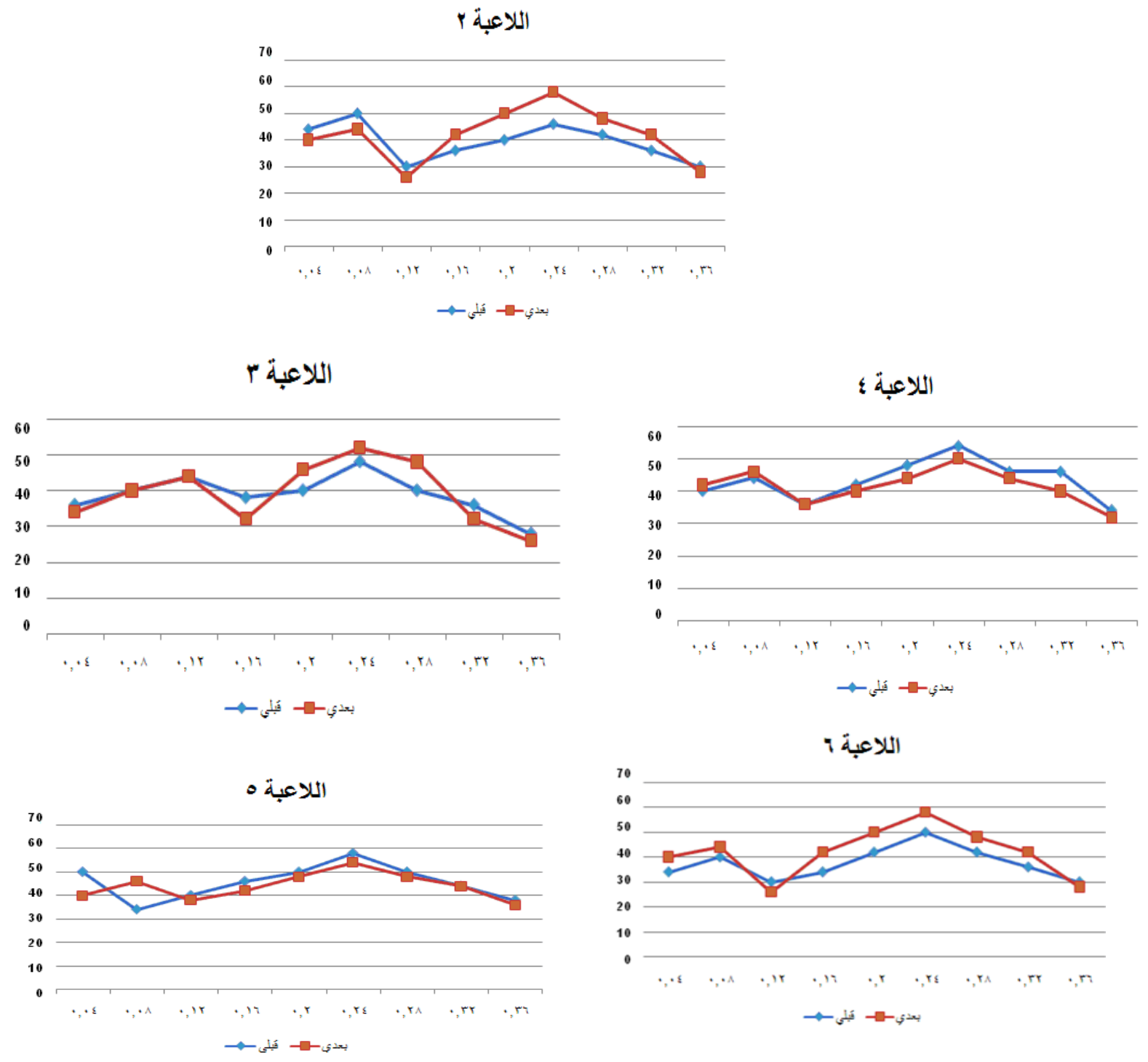

اللاعبة V

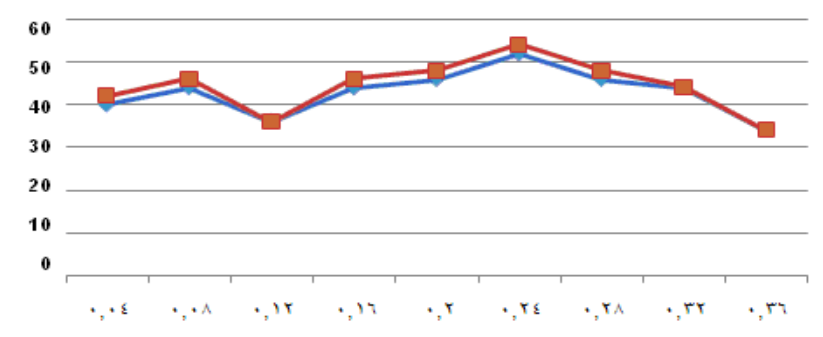

$$
\rightarrow \text { بxist }
$$

Figure (3) horizontal displacement values curve for body movement while performing the jump shooting skill in the two measurements (pre - post) for the female athletes. 


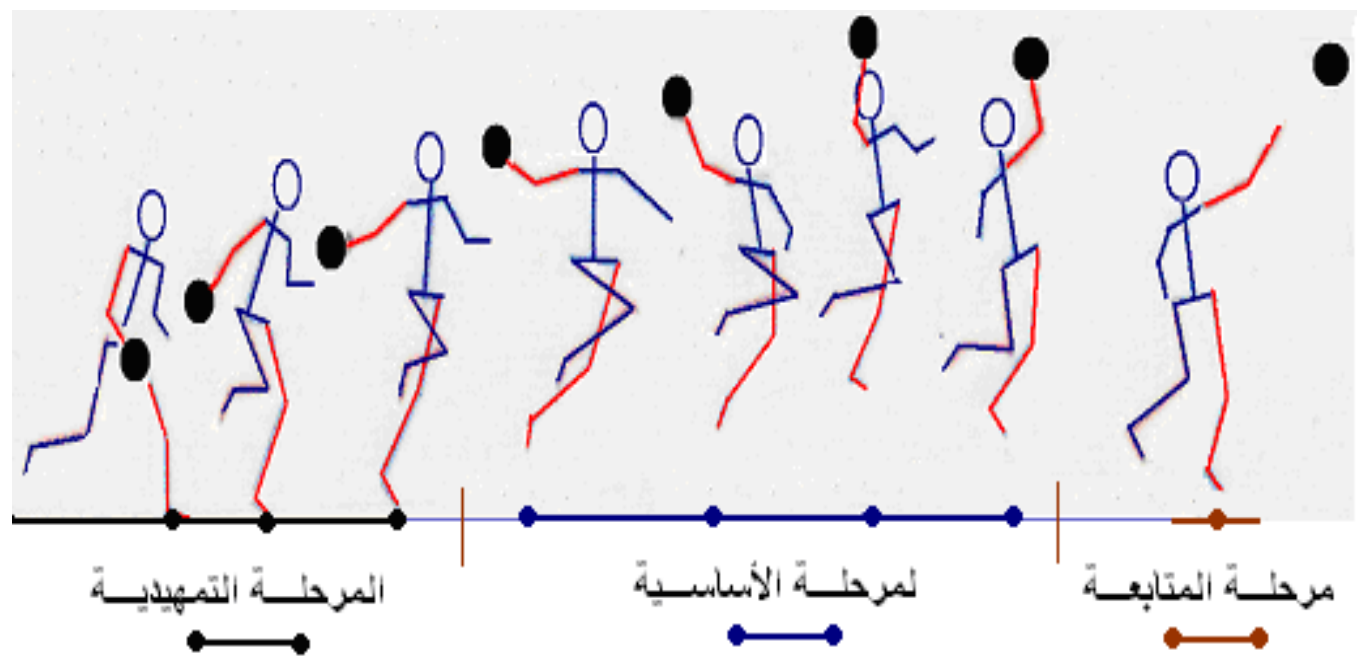

Pre Measurement

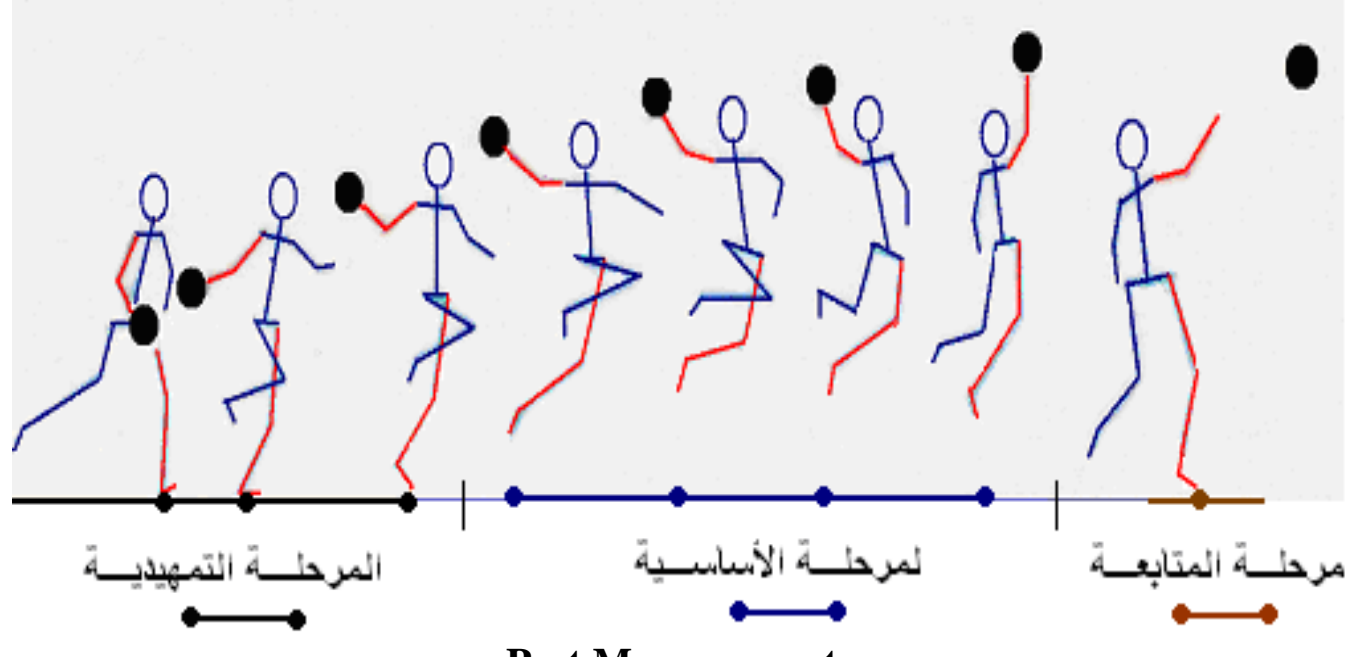

Post Measurement

Figure (4) the body parts kinematic path movement while performing the jump shooting skill in the two measurements (pre - post) of player (1)

3) Shooting arms hand movement horizontal displacement value while performing the jump shooting skill 
Table (8)

Shooting arm hand movement horizontal displacement $(\mathrm{cm})$ during the jump shot skill performance in the two measurements (pre-post) of the research sample

\begin{tabular}{|c|c|c|c|c|c|c|c|c|c|c|c|c|c|c|c|}
\hline \multirow[t]{2}{*}{ Statement } & \multirow{2}{*}{$\begin{array}{c}\text { Measure } \\
\text { unit }\end{array}$} & \multicolumn{2}{|c|}{ Player 1} & \multicolumn{2}{|c|}{ Player 2} & \multicolumn{2}{|c|}{ Player 3} & \multicolumn{2}{|c|}{ Player 4} & \multicolumn{2}{|c|}{ Player 5} & \multicolumn{2}{|c|}{ Player 6} & \multicolumn{2}{|c|}{ Player 7} \\
\hline & & Pre & Post & Pre & Post & Pre & Post & pre & Post & Pre & Post & Pre & Post & Pre & Post \\
\hline 0,04 & sec & 62 & 67 & 57 & 60 & 57 & 43 & 57 & 60 & 65 & 60 & 60 & 57 & 65 & 68 \\
\hline 0,08 & sec & 57 & 65 & 43 & 52 & 43 & 35 & 55 & 53 & 36 & 33 & 52 & 45 & 52 & 53 \\
\hline 0,12 & sec & 43 & 36 & 35 & 33 & 27 & 33 & 36 & 28 & 30 & 22 & 33 & 30 & 38 & 36 \\
\hline 0,16 & sec & 33 & 30 & 28 & 25 & 18 & 22 & 23 & 20 & 22 & 17 & 25 & 18 & 25 & 22 \\
\hline 0,2 & sec & 29 & 22 & 22 & 18 & 12 & 13 & 17 & 15 & 25 & 13 & 18 & 14 & 18 & 15 \\
\hline 0,24 & sec & 36 & 30 & 37 & 36 & 22 & 27 & 33 & 25 & 33 & 25 & 33 & 37 & 30 & 33 \\
\hline 0,28 & sec & 55 & 40 & 45 & 54 & 33 & 36 & 46 & 53 & 48 & 54 & 45 & 54 & 48 & 54 \\
\hline 0,32 & sec & 60 & 65 & 57 & 62 & 52 & 57 & 60 & 60 & 65 & 65 & 62 & 65 & 60 & 64 \\
\hline 0,36 & sec & 75 & 80 & 75 & 83 & 65 & 72 & 65 & 68 & 75 & 75 & 75 & 80 & 72 & 80 \\
\hline
\end{tabular}

Table (8) shows that the horizontal displacement change in values of the shooting arm hand movement during the jump shot skill performance in the two measurements (pre-post), and the table shaded part shows the start of the basic main movement start of the shooting arm until the moment the ball is released.

In light of the results presented in the previous table, the researcher can discuss these results as follows:

1. Shooting arm preparatory stage took two-thirds of the time to perform the arm movement from the beginning of the skill to its end. Table (8) identifies the shooting arm preparatory stage end at $(0.2 \mathrm{sec})$ time.

2. It is also noticed that there is a variation between the shooting arm hand movement horizontal displacement values between the pre and post measurements of the research sample. The researcher sees that the shooting hand movement displacement values increase in general from the beginning of the performance and then its declines with the preparatory stage end. The result of a change in the hand direction from front to backwards reversing the movement direction, and the decline in the preparatory stage post measurement values is a result of the shooting arm expanding and the increased muscle lengthening of the muscles involved in the movement, and increase the muscle stretching of the muscles involved in the movement. The more the shooting arm expands backwards the horizontal displacement values of the preparatory arm movement decline until the arm begins its backward movement with the arm main stage beginning.

3. The basic stage took a quick form of the shooting arm's hand path where the basic stage began with the arm's movement forward beginning towards the goal at a time $(0.24 \mathrm{sec})$ and ended with the launch moment (release) of the ball at a time of $(0.36 \mathrm{sec})$.

The researcher believes that the observed increase in the outputs of the main stage movement horizontal displacement values was a result of the shooting hand movement rapid transfer from back to front until the ball was launched from the player's hand, in addition to the rotation of the trunk, so the throwing process requires the participation of the rest of the body. For that the trunk helps motor transport from the lower to the upper extremities. 


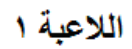

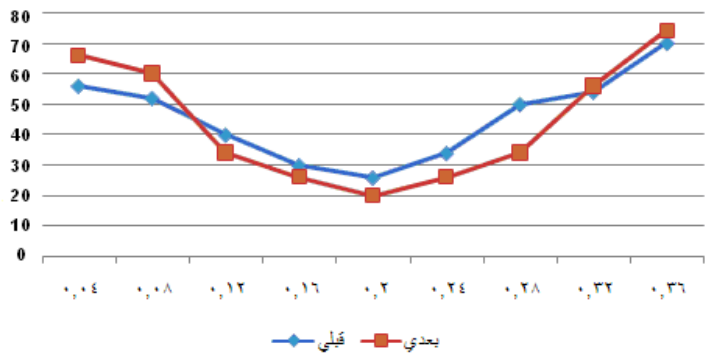

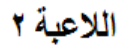
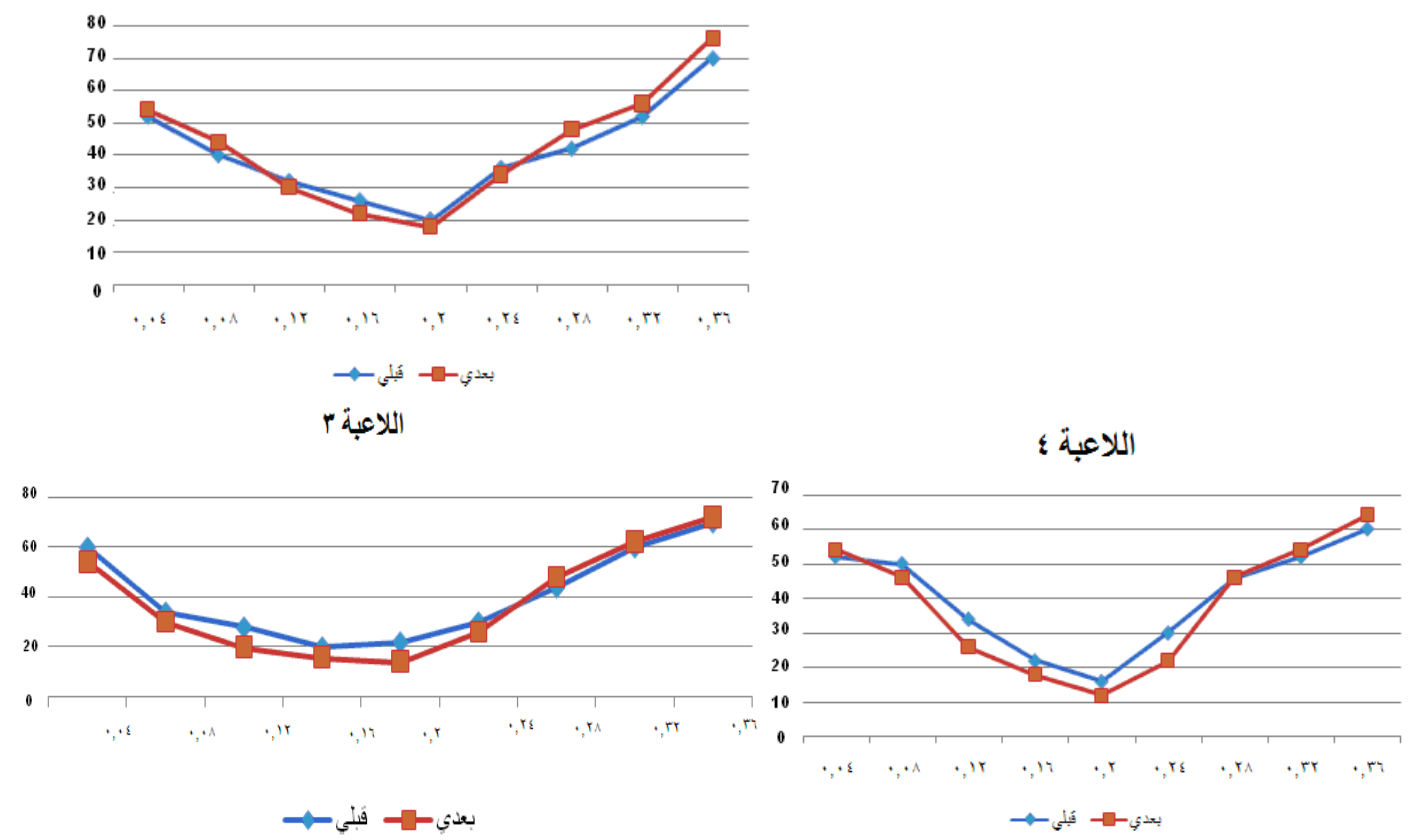

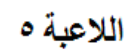
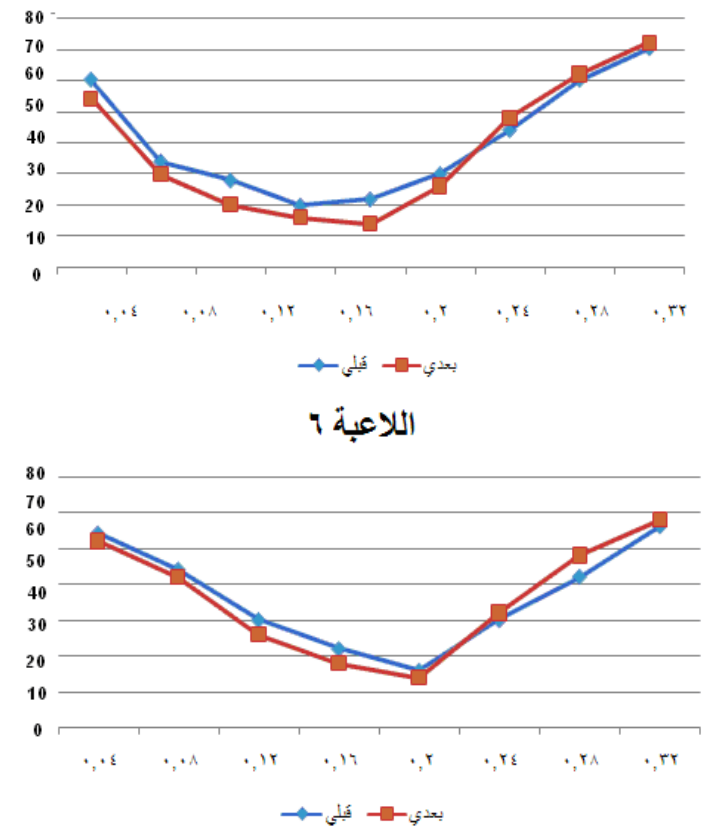


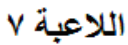

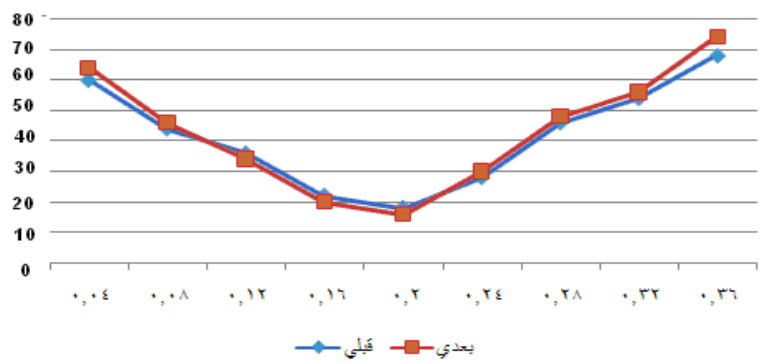

Figure (5) horizontal displacement values curve for the shooting arm's hand movement during the jump shooting skill performance in the two measurements (pre-post) for the research sample female player.

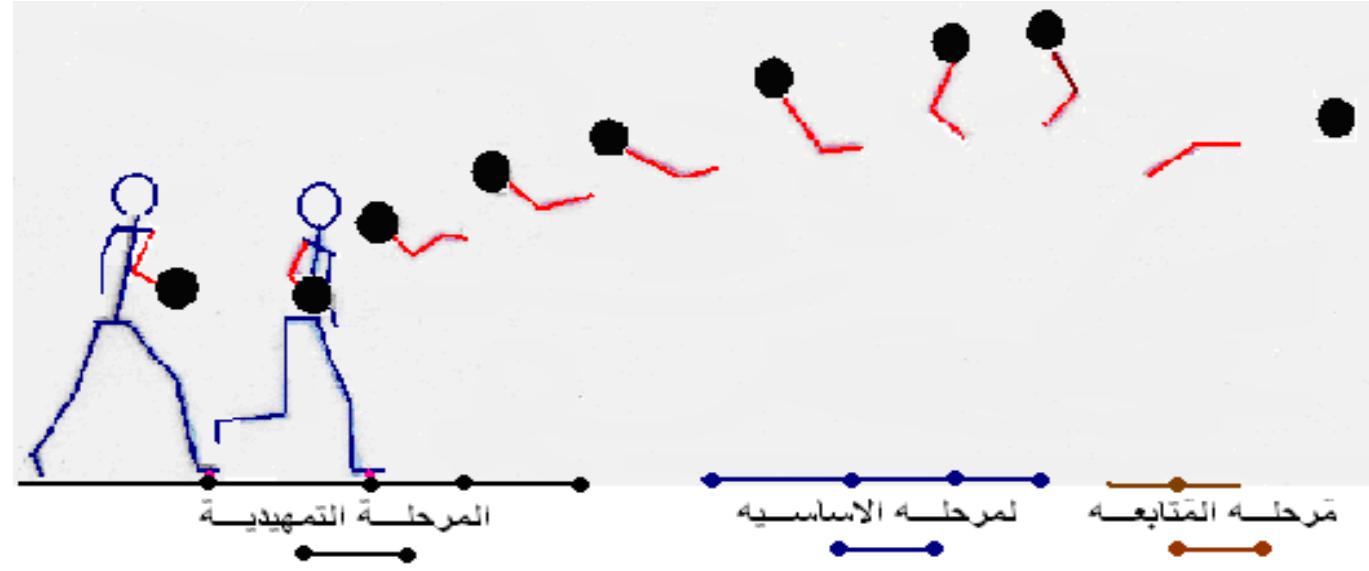

Pre Measurements

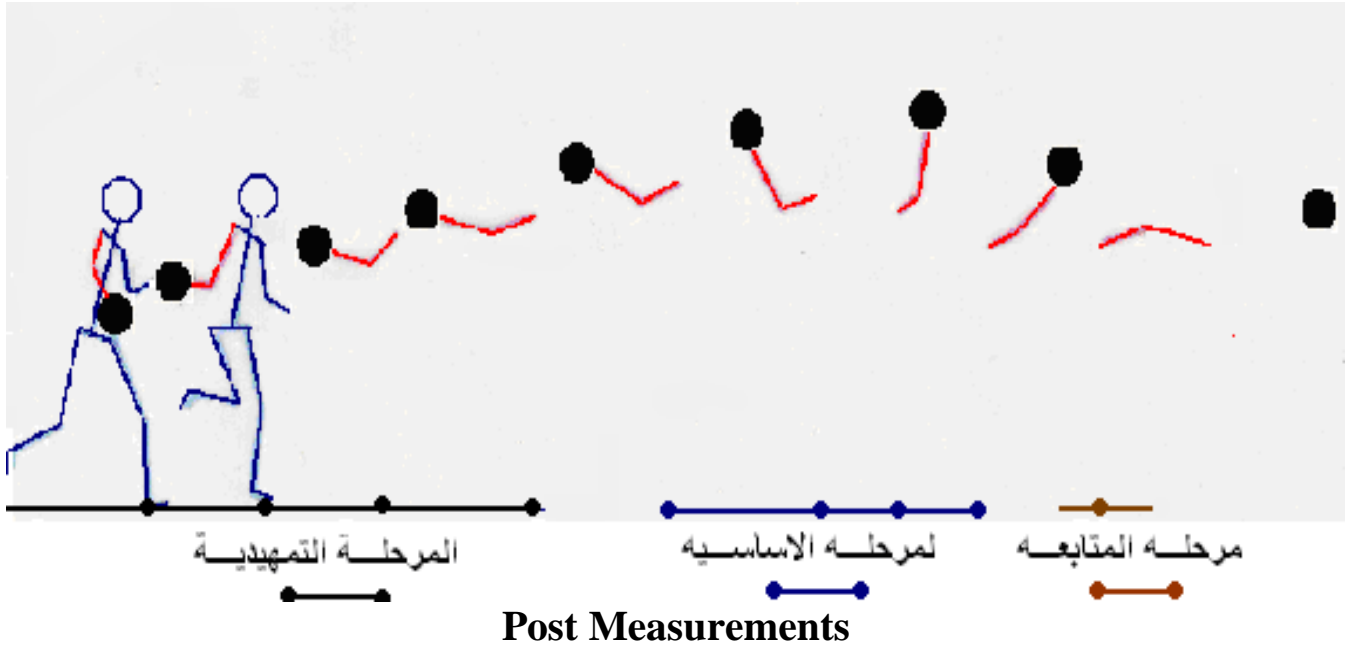

Figure (6) the kinematic path for the shooting arm movement while performing the jump shooting skill in the two measurements (before - after) for player (3)

4) Gravity center height rate on the vertical axis moment of elevating (launch) of the jump shooting skill 
Table (9)

Significant difference between the research sample pre and post measurements in the body's gravity center elevation position in the elevated foot release

moment on the vertical level (meters) $(n=7)$

\begin{tabular}{|c|c|c|c|c|}
\hline $\begin{array}{c}\text { Measuremen } \\
\text { ts }\end{array}$ & $\begin{array}{c}\text { Research sample gravity center } \\
\text { height value Mean }\end{array}$ & Minimum & Maximum & $\mathrm{Z}$ value \\
\hline Pre & $\mathbf{1 , 1 5 2}$ & $\mathbf{1 , 1 2}$ & $\mathbf{1 , 1 8}$ & \multirow{2}{*}{$\mathbf{0 , 8 5 0} *$} \\
\hline Post & $\mathbf{1 , 1 5 7}$ & $\mathbf{1 , 1 0}$ & $\mathbf{1 , 2 0}$ & \\
\hline
\end{tabular}

\section{$Z$ value at a level $(0.05)=0,773$}

By comparing the body's gravity center height values of the pre and post measurement of the research sample female players, it is noted that there is a slight variation in the gravity center height distance between the pre and post measurements, which was in the post measurement direction.

The researcher believes that the body's gravity center height at the elevation moment (launch) depends mainly on the extent of the player's ability to achieve the pushing leg full expansion at the release moment. This may be due to an improvement in the elevation foot work, especially the ankle, and this in turn is considered an improvement in the muscular work of the active muscle groups, especially the legs gastrocnemius muscle as an ankle flexor muscle. Therefore, the researcher believes that the core muscle exercises under study contributed in improving the muscular work of the active muscle groups in the process of pushing the elevation around the knee and foot joints in particular. In addition, the trunk straighten posture was improved by being in line with the pushing leg with the free leg swinging help. This is in agreement with Melvin P. Ramy (2005) in that the height of the body's center of gravity during a jump is affected by the force produced at the elevating moment. (www.iraqcad.org/forum)
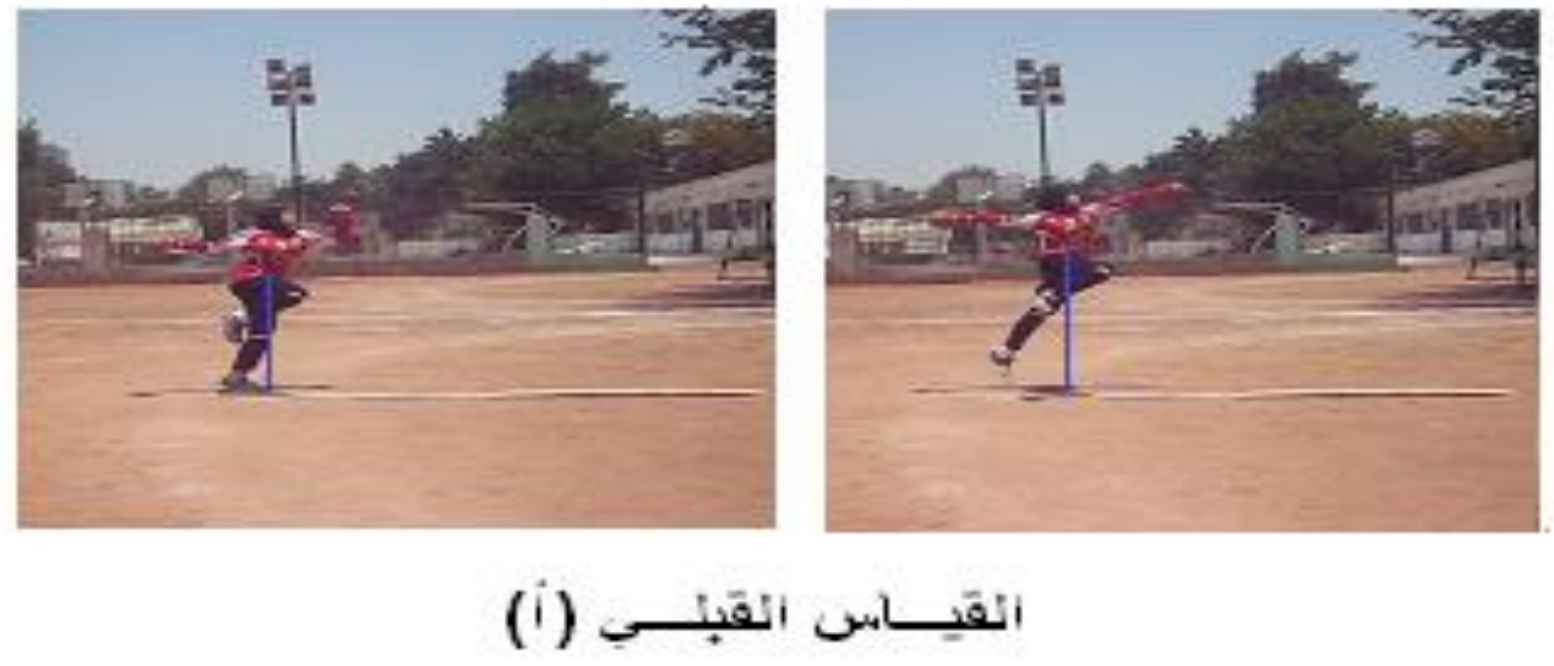

Pre Measurements (A) 

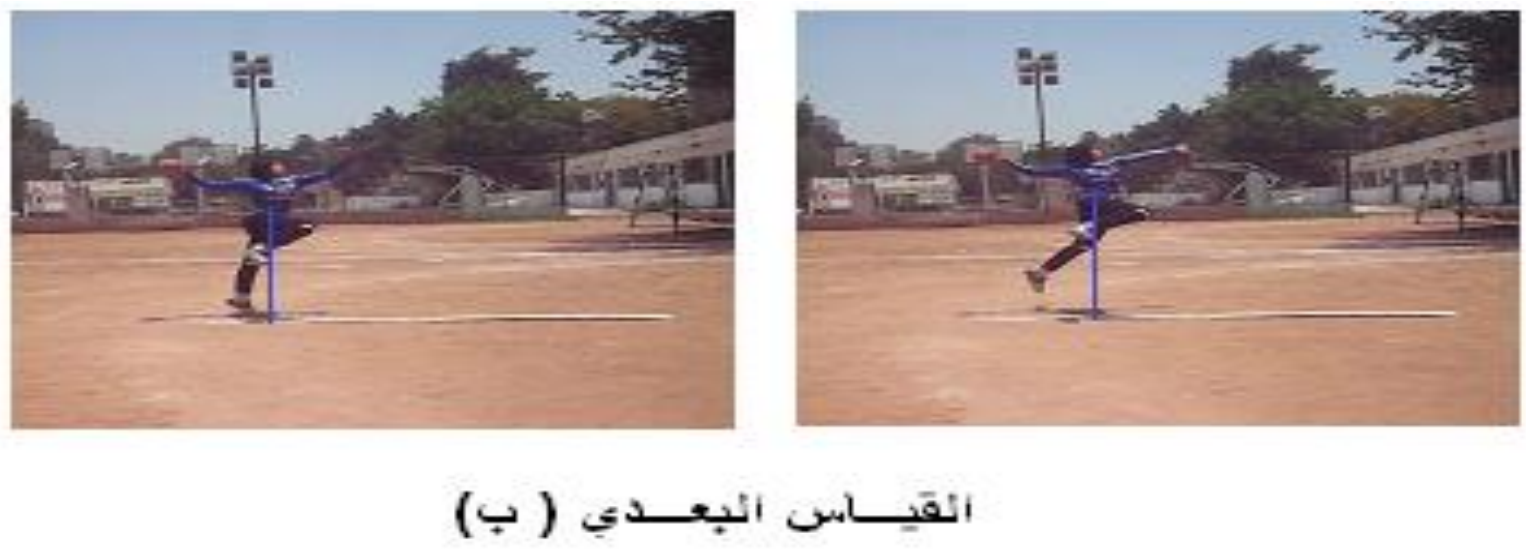

Post Measurements (B)

Figure (7) shows the difference between the body's gravity center height and the elevation moment

For pre-measurement (A) - post measurement (B)

5) The elevated foot vertical velocity components values at the body's launch moment (release) and the shooting arm horizontal velocity components at the ball launch moment (release).

Table (10)

Significance differences between the pre and post measurements of the elevated foot vertical velocity components values at the body's launch moment, and the ball horizontal velocity components at its launch moment of the research sample $(\mathrm{min} / \mathrm{sec})(\mathrm{n}=7)$

\begin{tabular}{|c|c|c|c|c|c|}
\hline \multirow{2}{*}{ Velocity Components } & \multicolumn{2}{|c|}{ Pre Measurements } & \multicolumn{2}{|c|}{$\begin{array}{c}\text { Post } \\
\text { Measurements }\end{array}$} & \multirow{2}{*}{ Z value } \\
\cline { 2 - 5 } & Mean - & SD \pm & Mean - & SD \pm & \\
\hline $\begin{array}{c}\text { Elevated foot vertical velocity } \\
\text { component launch moment }\end{array}$ & 3,735 & $\mathbf{0 , 9 1 5}$ & $\mathbf{4 , 7 9 2}$ & $\mathbf{1 , 0 1}$ & $\mathbf{2 , 3 7 1 *}$ \\
\hline $\begin{array}{c}\text { ball horizontal velocity } \\
\text { components launch moment }\end{array}$ & $\mathbf{1 0 , 4 5 7}$ & $\mathbf{1 , 3 5 2}$ & $\mathbf{2 0 , 4 4 8}$ & $\mathbf{2 , 0 9 2}$ & \multirow{2}{*}{$\mathbf{2 , 3 7 1 *}$} \\
\hline
\end{tabular}

\section{$Z$ value at a level $(0.05)=0,773$}

The researcher believes that the increase in the elevation foot at the body's launch moment instantaneous velocity for post measurement depends on the player's ability to obtain speed from the preparatory stage by taking advantage of the horizontal velocity gained from approaching and converting it into a vertical velocity at the elevating foot pushing moment.

Table (10) shows the increase in the shooting arm horizontal velocity at the ball's launching moment for post measurement. The researcher believes that this depends on increasing the shooting arm's hand motion range, as it increases the arm's movement path and increases the ball's speed in its launch moment. This, in turn, expresses the shooting arm muscular work improvement during the main stage performance (ability stage). In addition to taking advantage of the elevating foot speed, the free leg swinging and the trunk rapid rotation through the body parts kinetic transmission that works on the shooting arms movement path height and thus the ball launch quickly and forcefully in the goal direction. 
1) The angular change values of the shooting arm joints, the free leg, and the lift foot in some jump shooting performance positions.

Table (11)

The body angles value during the jump shot kinematic stages performance in pre and post measurements of the research sample $(n=7)$

\begin{tabular}{|c|c|c|c|c|c|c|c|c|c|c|c|c|c|c|c|}
\hline \multirow{2}{*}{\multicolumn{2}{|c|}{ Body angles variables }} & \multicolumn{2}{|c|}{ Player 1} & \multicolumn{2}{|c|}{ Player 2} & \multicolumn{2}{|c|}{ Player 3} & \multicolumn{2}{|c|}{ Player 4} & \multicolumn{2}{|c|}{ Player 5} & \multicolumn{2}{|c|}{ Player 6} & \multicolumn{2}{|c|}{ Player 7} \\
\hline & & Pre & Post & Pre & Post & Pre & Post & pre & Post & Pre & Post & Pre & Post & Pre & Post \\
\hline \multicolumn{2}{|c|}{$\begin{array}{l}\text { shooting arm elbow angle at the } \\
\text { preparatory motion end }\end{array}$} & 135 & 170 & 135 & 140 & 105 & 150 & 115 & 140 & 105 & 140 & 120 & 155 & 110 & 130 \\
\hline \multicolumn{2}{|c|}{ elbow angle ball release moment } & 85 & 100 & 103 & 110 & 115 & 105 & 115 & 100 & 90 & 100 & 105 & 100 & 95 & 105 \\
\hline \multicolumn{2}{|c|}{$\begin{array}{r}\text { elevation foot angles, launch moment } \\
- \text { instep touch ground }\end{array}$} & 110 & 115 & 95 & 125 & 91 & 125 & 117 & 115 & 127 & 130 & 115 & 120 & 105 & 115 \\
\hline \multicolumn{2}{|c|}{$\begin{array}{c}\text { incline angle elevating moment } \\
\text { (release })\end{array}$} & 5 & 10 & 10 & 15 & 10 & 12 & 12 & 14 & 10 & 15 & 8 & 15 & 10 & 11 \\
\hline \multirow[t]{3}{*}{ free foot angle before launch } & thigh & 45 & 70 & 60 & 38 & 45 & 57 & 30 & 50 & 35 & 45 & 45 & 40 & 40 & 130 \\
\hline & knee & 50 & 50 & 44 & 65 & 55 & 55 & 54 & 95 & 50 & 60 & 50 & 50 & 55 & 105 \\
\hline & ankle & 125 & 135 & 93 & 132 & 65 & 90 & 105 & 115 & 110 & 135 & 105 & 110 & 110 & 115 \\
\hline \multirow{3}{*}{$\begin{array}{l}\text { free foot angles at the body } \\
\text { launch in air moment }\end{array}$} & thigh & 25 & 22 & 44 & 33 & 45 & 42 & 34 & 75 & 40 & 30 & 35 & 30 & 40 & 10 \\
\hline & knee & 53 & 67 & 52 & 52 & 65 & 38 & 62 & 95 & 60 & 50 & 55 & 50 & 65 & 40 \\
\hline & ankle & 70 & 137 & 90 & 120 & 100 & 91 & 118 & 112 & 95 & 130 & 105 & 110 & 110 & 50 \\
\hline \multirow{3}{*}{$\begin{array}{c}\text { Free leg angle with the } \\
\text { shooting arm preparatory } \\
\text { end movement }\end{array}$} & thigh & 35 & 23 & 74 & 29 & 53 & 42 & 54 & 52 & 95 & 30 & 45 & 30 & 50 & 105 \\
\hline & knee & 45 & 50 & 75 & 44 & 105 & 110 & 78 & 125 & 125 & 45 & 70 & 55 & 80 & 40 \\
\hline & ankle & 65 & 135 & 110 & 134 & 110 & 135 & 130 & 140 & 90 & 142 & 110 & 105 & 115 & 55 \\
\hline \multirow{3}{*}{$\begin{array}{l}\text { Free leg angle in the body's } \\
\text { flight path top }\end{array}$} & thigh & 45 & 35 & 70 & 20 & 40 & 40 & 90 & 90 & 40 & 15 & 50 & 35 & 45 & 110 \\
\hline & knee & 28 & 55 & 68 & 45 & 70 & 52 & 117 & 115 & 60 & 35 & 70 & 60 & 65 & 45 \\
\hline & ankle & 55 & 147 & 110 & 97 & 75 & 147 & 110 & 120 & 70 & 90 & 110 & 105 & 115 & 60 \\
\hline
\end{tabular}

Table (11) shows the angular change values of some body parts joints (shooting arm - free leg - elevating foot) in some jump shooting 
As for the shooting arm elbow angle at the preparatory movement end, the obtuse angle has increased in the post measurement than in the pre measurement, since the obtuse angle gives a wider motion range for the shooting arm movement. As for the elbow angle at the moment the ball is released, it is a slightly obtuse angle compared to the elbow angle at the end of the preparatory movement, and it may be less than the same angle in the skill pre measurement for some players such as player (3), player (4) and player (6). The basic shooting arm movement appears with the start by moving the shoulder forward towards the goal, followed by the elbow, then the hand and the ball, and the elbow joint angle is reduced for some players in the post measurement, as a result of the increase in the muscular contraction force that helps to quickly get rid of the ball at the flying phase end.

The researcher believes that the strength development and core muscles ability positively affected the arm's muscular capacity, which affected the shooting arm muscular work by providing the opportunity for muscles sufficient stretching before contracting to perform the basic movement, which can be expressed as the ability stage to complete the shooting process by launching the ball towards the goal.

As for the elevating foot ankle angle at the body's launching moment and the instep touching the ground in the post measurement, was more than the amount of the same angle in the pre measurement. As the slightly obtuse angle in the post measurement is an indicator of the improvement in the elevating foot work by increasing the ankle expansion, which increases the player's ability in the elevation foot pushing the ground process. This is in agreement with "Wilf Paish" (1998) that the jump success is determined by calculating the starting angle at the last point the elevation foot contacted the ground.

The body's inclination angle at the elevation moment, increased in the post measurement than in the pre measurement. The researcher believes that the body's inclination angle at the elevation moment is what enables the player to expand the body joints (thigh, knee, ankle), that pushes the player to launch in the air. Whereas, the inclination angle is determined by the body's gravity center movement forward and upward over the elevating foot with the help of swinging the shooting arm backward, the trunk rotation and the free leg strongly upwards harmonizes with the elevating foot joints expansion (thigh, knee, and ankle), this expansion pushes the player into the air.

The free leg angular change before, at the launch moment, at the shooting arm preparatory movement end and at the flight path top was in some pre measurements exaggerated obtuse angles where the performance was marred by many errors that were corrected in the post measurements; this may be result of the core muscle training. The players were able to take appropriate joint angles for the joint involved in performance, which allows the best stretching and prepares the muscles to contract quickly and strongly, which helped in skill performance the skill in the correct mechanical way. This is in agreement with "Khairia Ibrahim El Sokar, Mohamed Gaber Berekaa" (2002) in that performing the skill in the correct mechanical way enables the player to make good use of all body joints to obtain a technically correct movement. 
Table (12)

Angular change values improvement rates of some body positions and parts for the pre and post measurements $(n=7)$

\begin{tabular}{|c|c|c|c|c|c|c|}
\hline \multicolumn{2}{|c|}{ Body angles variables } & $\begin{array}{l}\text { Reference } \\
\text { frame }\end{array}$ & $\begin{array}{c}\text { Pre } \\
\text { measurements } \\
\text { Mean }\end{array}$ & $\begin{array}{l}\text { Post } \\
\text { Measurements } \\
\text { Mean }\end{array}$ & Differences & $\%$ \\
\hline \multicolumn{2}{|c|}{$\begin{array}{c}\text { shooting arm elbow angle } \\
\text { at the preparatory motion } \\
\text { end }\end{array}$} & Relative & $119^{\circ}$ & $146^{\circ}$ & $27^{\circ}$ & 23 \\
\hline \multicolumn{2}{|c|}{$\begin{array}{c}\text { elbow angle ball release } \\
\text { moment }\end{array}$} & Relative & $101^{\circ}$ & $108^{\circ}$ & $7^{\circ}$ & 7 \\
\hline \multicolumn{2}{|c|}{$\begin{array}{l}\text { elevation foot angles, } \\
\text { launch moment - instep } \\
\text { touch ground }\end{array}$} & Relative & $113^{\circ}$ & $116^{\circ}$ & $3^{\circ}$ & 3 \\
\hline \multicolumn{2}{|c|}{$\begin{array}{c}\text { incline angle elevating } \\
\text { moment (release ) }\end{array}$} & Absolute & $10^{\circ}$ & $11^{\circ}$ & $1^{\circ}$ & 10 \\
\hline \multirow{3}{*}{$\begin{array}{l}\text { free foot angle } \\
\text { before launch }\end{array}$} & thigh & Relative & $43^{\circ}$ & $49^{\circ}$ & $6^{\circ}$ & 14 \\
\hline & knee & Relative & $51^{\circ}$ & $61^{\circ}$ & $10^{\circ}$ & 2 \\
\hline & ankle & Relative & $102^{\circ}$ & $117^{\circ}$ & $15^{\circ}$ & 15 \\
\hline \multirow{3}{*}{$\begin{array}{l}\text { free foot angles at } \\
\text { the body launch in } \\
\text { air moment }\end{array}$} & thigh & Relative & $37^{\circ}$ & $39^{\circ}$ & $2^{\circ}$ & 4 \\
\hline & knee & Relative & $48^{\circ}$ & $60^{\circ}$ & $12^{\circ}$ & 2 \\
\hline & ankle & Relative & $98^{\circ}$ & $116^{\circ}$ & $18^{\circ}$ & 18 \\
\hline \multirow{3}{*}{$\begin{array}{l}\text { Free leg angle with } \\
\text { the shooting arm } \\
\text { preparatory end } \\
\text { movement }\end{array}$} & thigh & Relative & $32^{\circ}$ & $36^{\circ}$ & $4^{\circ}$ & 12 \\
\hline & knee & Relative & $82^{\circ}$ & $90^{\circ}$ & $8^{\circ}$ & 10 \\
\hline & ankle & Relative & $104^{\circ}$ & $129^{\circ}$ & $25^{\circ}$ & 24 \\
\hline \multirow{3}{*}{$\begin{array}{l}\text { Free leg angle in } \\
\text { the body's flight } \\
\text { path top }\end{array}$} & thigh & Relative & $34^{\circ}$ & $39^{\circ}$ & $5^{\circ}$ & 15 \\
\hline & knee & Relative & $68^{\circ}$ & $70^{\circ}$ & $2^{\circ}$ & 3 \\
\hline & ankle & Relative & $92^{\circ}$ & $117^{\circ}$ & $25^{\circ}$ & 27 \\
\hline
\end{tabular}

Table (12) shows the change rate (improvement rate) for the angular change values for some body places and its parts that occurred between the research sample pre and post measurements. The improvement rates ranged between $(2 \%-27 \%)$, and the highest improvement rates were in favor of the free leg angle variable at the top of the body's flying path.

The researcher believes that the change values in favor of technical performance on one hand and the benefit from proceeds of the body core muscles muscle strength development, as well as the active body parts strength and ability development in the skill performance of jump shooting on the other side. Although the percentage values varied according to the mechanical variable pattern, the most obvious changes are the free-leg angle at the body's flight path top and the elbow joint angle (forearm- humerus) at the shooting arm preparatory movement end. This helps improve muscular work during the main stage performance (the ability stage), in addition to increasing the shooting arm hand motion range, which increases arm movement path and increases the ball speed at the launch moment in the goal direction. 


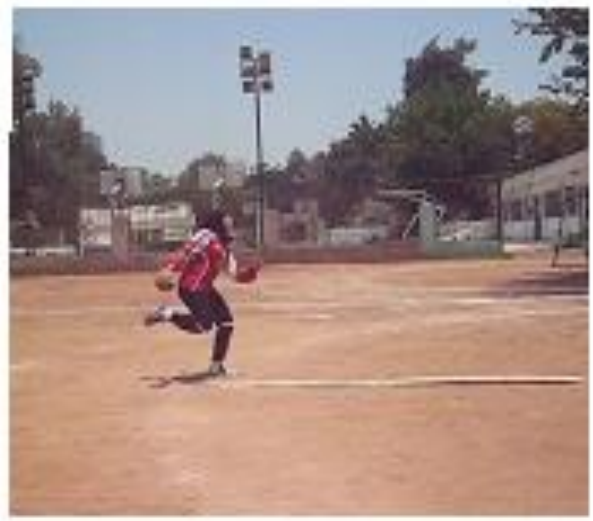

Free Leg Angles before Launch (A)

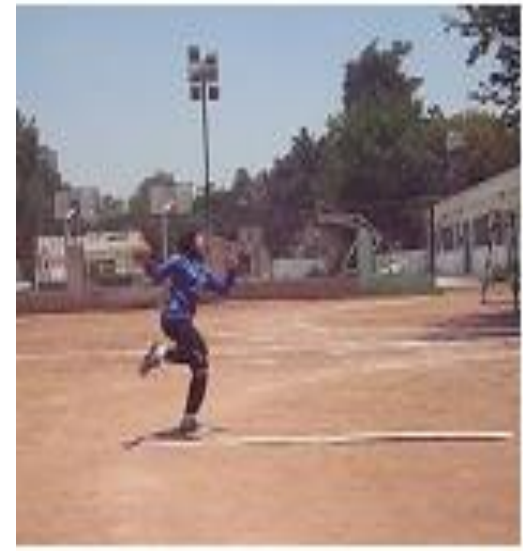

Free Leg Angles before Launch (B)

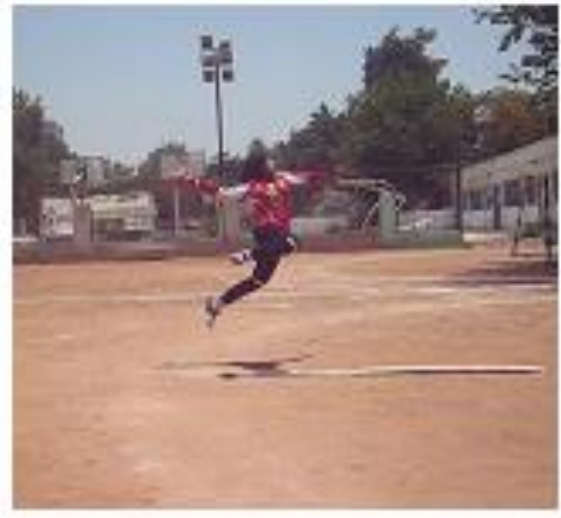

Free leg angles are at the body's

flight path top (A)

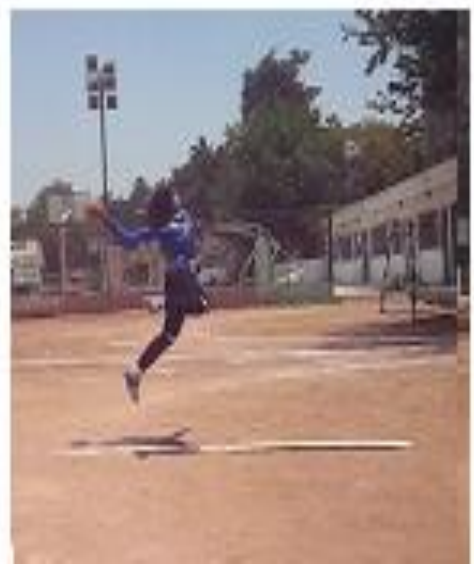

Free leg angles are at the body's

flight path top (B)

Figure (8) Pictures some body angles while performing the shooting jump kinetic stages in the pre (A) - post (B) measurements.

From the above, the first hypothesis has been partially answered, that states: There are statistically significant differences between the pre and post measurements in some biomechanical variables values that affect the long jump shooting skill performance of the research sample handball female players in favor of the post measurement.

Second: The physical and skill variables results of the research sample: 
Table (13)

Significance differences and change rate between the pre and post measurements in the physical and skill variables of the research sample $(n=7)$

\begin{tabular}{|c|c|c|c|c|c|c|c|c|c|c|}
\hline & \multirow{2}{*}{ Tests } & \multirow{2}{*}{$\begin{array}{c}\text { M } \\
\text { unit }\end{array}$} & \multicolumn{2}{|c|}{ Pre } & \multicolumn{2}{|c|}{ Post } & \multirow{2}{*}{$\begin{array}{l}\text { Avera } \\
\text { ge rate }\end{array}$} & \multirow{2}{*}{$\begin{array}{c}\mathbf{Z} \\
\text { value }\end{array}$} & \multirow{2}{*}{$\begin{array}{c}\text { Signific } \\
\text { ance }\end{array}$} & \multirow{2}{*}{$\begin{array}{l}\text { Change } \\
\text { rate \% }\end{array}$} \\
\hline & & & Mean & SD & Mean & SD & & & & \\
\hline \multirow{24}{*}{ 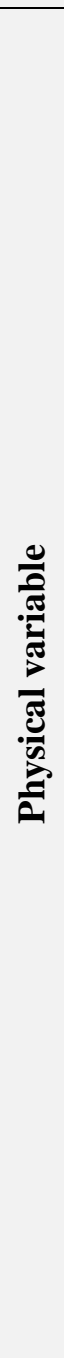 } & \multirow[b]{2}{*}{ Legs strength (Dynamometer) } & \multirow{2}{*}{ Kg } & \multirow{2}{*}{68,00} & \multirow{2}{*}{14,49} & \multirow{2}{*}{ 70,31 } & \multirow{2}{*}{2,11} & $\mathbf{0 , 0 0}$ & \multirow{2}{*}{$2,36-$} & \multirow{2}{*}{$\mathbf{0 , 0 1 7 *}$} & \multirow{2}{*}{22,48} \\
\hline & & & & & & & 4,00 & & & \\
\hline & \multirow[b]{2}{*}{ Back strength(Dynamometer) } & \multirow[b]{2}{*}{ Kg } & \multirow[b]{2}{*}{64,28} & \multirow[b]{2}{*}{12,39} & \multirow{2}{*}{71,21} & \multirow[b]{2}{*}{1,01} & $\mathbf{0 , 0 0}$ & \multirow[b]{2}{*}{$2,37-$} & \multirow{2}{*}{$0,017 *$} & \multirow[b]{2}{*}{16,25} \\
\hline & & & & & & & 4,00 & & & \\
\hline & \multirow[b]{2}{*}{ Sit ups (20 sec) } & & & & & & $\mathbf{0 , 0 0}$ & & $0017 *$ & \\
\hline & & Repeat & 21,57 & 4,03 & 35,54 & 1,11 & 4,00 & 2,37- & $0,017^{*}$ & 46,13 \\
\hline & & Repeat & 18,57 & 3,10 & 24,66 & 4,811 & $\mathbf{0 , 0 0}$ & 2,36- & $\mathbf{0 , 0 1 7 *}$ & 54,16 \\
\hline & Push ups & Repeat & $18,5 /$ & 3,10 & 24,00 & 4,811 & 4,00 & $2,90^{-}$ & $0,01 /$ & 54,10 \\
\hline & & $\mathbf{C m}$ & 148 & 852 & 1573 & 785 & $\mathbf{0 , 0 0}$ & 237 & $0.017 *$ & 63 \\
\hline & Standing broad jump & CIm & 140 & $0, \mathbf{3 z}$ & $15 /, 3$ &, $\mathbf{0 5}$ & 4,00 & $2,3 /-$ & $0,01 / \cdots$ & $\mathbf{0 , 5}$ \\
\hline & & $\mathrm{Cm}$ & 176.3 & 24.34 & 2097 & 34.80 & $\mathbf{0 , 0 0}$ & $236-$ & $0.017 *$ & 18.9 \\
\hline & Broad jump (3 steps) & & & & & & 4,00 & & & \\
\hline & & $\mathrm{Cm}$ & 2257 & 496 & 29.4 & 287 & $\mathbf{0 , 0 0}$ & $237-$ & $0.017 *$ & 307 \\
\hline & Vertical jump with swing arms & $\mathrm{Cm}$ & $22,3 /$ & 4,90 & 29,4 & $2, \mathbf{0} /$ & $\mathbf{4 , 0 0}$ & 2,3/- & & \\
\hline & & $\mathrm{Cm}$ & 18.57 & 2.29 & 23.28 & 281 & $\mathbf{0 , 0 0}$ & $237-$ & $0.017 *$ & 25.4 \\
\hline & Vertical jump without swing arms & CiII & & & & & 4,00 & & 0,011 & $2 \mathfrak{J}, \mathbf{4}$ \\
\hline & & Meter & 535 & 078 & 806 & 166 & $\mathbf{0 , 0 0}$ & 236 & $0017 *$ & 506 \\
\hline & Medicine ball trunk rotation throw & ineter & $\mathbf{5 , 3 0}$ & $0, / 0$ & $\mathbf{0 , 0 0}$ & 1,00 & 4,00 & $2,90^{-}$ & $0,01 / 4$ & 50,0 \\
\hline & & & & & & & $\mathbf{0 , 0 0}$ & & & \\
\hline & $\begin{array}{l}\text { Medicine ball trunk rotation (30 } \\
\text { sec) }\end{array}$ & Repeat & 19,57 & 1,81 & 28 & 2,64 & 4,00 & $2,41-$ & $\mathbf{0 , 0 1 5 *}$ & 43,1 \\
\hline & & & & & & & $\mathbf{0 , 0 0}$ & & & \\
\hline & $\begin{array}{l}\text { Throwing medicine ball to } \\
\text { farthest point }\end{array}$ & Meter & 7,19 & $\mathbf{1 , 4 5}$ & 9,11 & 1,92 & 4,00 & 2,36- & $\mathbf{0 , 0 1 7 *}$ & 26,7 \\
\hline & & & & & & & $\mathbf{0 , 0 0}$ & & & \\
\hline & $\begin{array}{l}\text { Strength\& stability of core } \\
\text { muscles }\end{array}$ & Grade & 41,25 & 0,98 & 71,21 & 0,54 & 4,00 & 2,36- & $0,017 *$ & 72,6 \\
\hline & & & & & & & $\mathbf{0 , 0 0}$ & & & \\
\hline $\overrightarrow{\frac{\pi}{\pi}}$ & $\begin{array}{l}\text { Long jump shot\& calculatıng fly } \\
\text { distance }\end{array}$ & $\mathrm{m}$ & $1, \mathbf{8 8}$ & $\mathbf{0 , 2 7}$ & 2,05 & $\mathbf{0 , 2 9}$ & 4,00 & 2,39- & 0,017* & $\mathbf{9 , 0 4}$ \\
\hline$\stackrel{\bar{z}}{\bar{z}}$ & Long jump shot accuracy on goal & ade & 4797 & 9.17 & 51.06 & 8.77 & $\mathbf{0 , 0 0}$ & $237-$ & $0.018 *$ & 14.4 \\
\hline$\frac{4}{\pi}$ & corners & & & & & & 4,00 & & & \\
\hline
\end{tabular}

Significance $\leq(\mathbf{0 , 0 5})$

in favor of the post measurement. It is also clear from table (13) that the improvement rates in the physical tests ranged between (72.6\% and 6.3\%), and the highest improvement rates was in favor of testing the core strength and stability.

The researcher attributes the improvement occurrence to the good planning of the core muscle training program and the training loads regulations in a scientific manner appropriate 
with the age and training phase of the research sample. She used the Swiss ball exercises, light weights and using body weight as a core strength training major part in order to develop muscular strength, where the researcher took into account the training with gradual loads during the program implementation by training the various muscle groups, especially the core part muscles.

This is in agreement with both "Skip \& Allen" (2002) that the most important benefits resulting from practicing exercises to strengthen the body's core part muscles are to increase motor efficiency during exercise, increase the body stability, and produce tremendous strength from the body's core part muscles as well as the adjacent muscles (shoulder, arms, and legs). The velocity strength characteristic improvement (muscular capacity), the activity of the rubber reflex allows excellent strength characterized transfer by velocity to the same biomechanically similar movements that require the trunk and the legs high capacity.

In this regard, Dave Schmitz (2003) points out that strong core muscles connect the lower extremities to the upper extremities, in addition to that core strength training includes multidirectional movements, making it one of the best exercises used to improve core muscle strength. (Middle body)

The table also shows statistically significant differences between the pre and post measurements in favor of the post measurement in the skill tests of the jump shot skill of the research sample. The researcher attributes this result to the core muscle training program, which led to an improvement in the legs and arms muscle strength and ability. The success of the shot skill requires the legs ability so that the player can jump forward to the maximum distance, as well as the arms strength and ability so that the shot is characterized by strength, speed and accuracy.

The core muscles exercises led to strengthening the trunk muscles, which has a great impact on the skill performance. This is in agreement with Reita (1997), who pointed that the aiming strength depends on the trunk rapid rotation, also in line with "Leith Ibrahim" (2009), who indicates that the shot skill performance skill requires many muscle groups participation beside the arms and shoulder in order to perform it with the required efficiency. This is done by transferring the force generated from the foot muscles through the trunk to end with the ball leaving the shooting palm, which requires a movement transfer in which the force is transferred between the body parts and applied in a way that ensures that the shot is stronger and faster as possible.

From the above, the first hypothesis has been partially answered, that states: There are statistically significant differences between the pre and post measurements in the muscle strength level (legs, trunk, arms), as well as the jump shooting skill level of the research sample handball female players in favor of the post measurement.

\section{Conclusions}

In light of the research objectives, within the research sample limits, from the data and information that the researcher has reached, and in statistical treatments light, the following were concluded:

1. The differences between the stages time distribution of the jump shooting skill performance in the pre and post measurements were statistically significant in both the preparatory and the main stage in favor of the post measurement, the variation in the follow-up phase time is equivalent, and the time distribution is summarized as follows:

- $\quad$ The average total time to perform the skill was approximately $(0.4 \mathrm{~s})$.

- The skill preparatory movement represented in (approach, elevate and arm movement 
aiming backward) represents approximately (50\%) of the players performance time in general according to the general situation and in particular according to the development processes during the player's training program.

- The skill basic movement, which was represented in (flying and the arm movement aiming the goal) represents $(30 \%)$ of the skill performance total time and with an ability time $(0.12 \mathrm{~s})$ for all research sample players, in the post measurement of the jump shot skill performance.

2. The core muscle exercises under study helped increase the elevating strength (pushing) and the body's launch speed.

3. Increasing the ankle range and pushing the free leg at the body launching moment is reflected in the body's gravity center height at the launch moment to complete the shot.

4. The change in values percentage variation $(\%)$ of the biomechanical variables is fitting to the job function and is in favor of performance.

5. Research sample strength and muscle ability measurements (legs - trunk - arms) were statistically significant in favor of the post measurements.

6. The change highest percentage improvement in muscular work for strength output and muscular ability among the three body parts (legs - trunk - arms) was the largest for the core area.

\section{Recommendations}

Within the research limits, its sample, and methodology used, and through the results, the researcher recommends the following:

1. Coaches making use of the research results as indicators through which to infer the player's physical performance characteristics.

2. Paying attention to the muscular work characteristic analysis and its parts during the handball skills performance generally and shooting specifically.

3. Paying attention to training the involved muscles during jump shot by applying more core muscle exercises within the training units.

4. Paying attention to training the players on the preparatory stage shot performance in a good way because of its important impact on the main stage.

5. Paying attention to developing muscle strength and ability for the trunk region for its role in the motor transport from the lower extremities to the upper extremities and achieving more motor control in the parts movement to serve the skill performance objective.

6. Increasing scientific research to support performance tests by using the mechanical variable values to evaluate the performance level.

\section{References List:}

\section{First: Arabic References}

1. Adel Abd El Basir Ali, Ihab Adel Abd El Basir (2007): Biomechanical Analysis (Integration between Theory and Practice in the Sports Field), Central Library for Printing and Publishing (394-396).

2. Amal Gaber Berikaa (2008): Biomechanics Principles and their Applications in the Sports Field, Dar Al-Wafaa Le Donia for Printing and Publishing, Alexandria. (17-60).

3. Fathy Ahmed Hady (2010): Modern Scientific Training in Handball, Horus International Foundation.

4. Kamal Abd El Hamid Ismail, Mohamed Sobhy Hassanein (2010): The Modern Handball Quad, Book Center for Publishing, Cairo. 
5. Kamal El Din Darwish, Kadri Sayed Morsy, Emad El Din Abbas (2002): Measurement, Evaluation, and Game Analysis in Handball, Theories - Applications, 1st Edition, Book Center for Publishing, Cairo. (125-130)

6. Khairia Ibrahim El Sokkari, Mohamed Gaber Berekaa (2002): Biomechanics Basic Principles in Sports Field, Part One, Knowledge Foundation in Alexandria. (120-124)

7. Laila El Sayed Farhat (2005): Measurement and Examination in Physical Education, 3rd Edition, Book Center for Publishing, Cairo. (71)

8. Leith Ibrahim Jassim Al-Azizi (2009): "Special strength and its relationship with the shot strength and accuracy during different physical effort levels for handball youth players aged (18-20)", Physical Education Science Journal, Volume Two, Issue Three, Syria. (110-133)

9. Mohamed Khalil Mohamed El Akidy (2004): Biochemical analysis of some shot skill variables from high jumping and their relationship with the handball shooting accuracy, Unpublished PhD thesis, KTR, Mosul University, Baghdad. (16)

10. Mohamed Said Soliman Abu Samra (2006): Plyometric Program Effectiveness on Some Kinematic Variables for the high jump in Hhandball for the Palestinian National Team, Unpublished Master's Thesis, Faculty of Physical Education, Tanta University.

11. Mohamed Sobhy Hassanein (2001): Measurement and Evaluation in Physical Education and Sports, 4th Edition, Arab Thought House, Cairo.

12. Mounir Gerges Ibrahim (2004): Handball for all (comprehensive training and skill excellence), Arab Thought House, Cairo. (145)

13. Talha Hossam E Din, Mohamed Fawzy Abd El Shakor, Mohamed El Sayed Helmy (2006): Motor Control (Principles - Theories - Applications), 1st Edition, Book Center for Publishing, Cairo. (75)

\section{Second: English References}

14 - Aishe El Fateh (2011): "The Effect of Core Strengthening on Physical Variables and Performance Level of Lung Among Young Female Fencers" Sport and science, National Sport Academy, Bulgira, 1000, Sofia, blv.v.levski, no75.(97-121)

15 - Akuthota, V., and S.F. Nadler. (2004): Core strengthening. Arch. Phys. Med. Rehabil. 85:86y92.(68)

16 - Allen, Skip (2002): "Core strength Training", science institute sports science Exchange roundtable, USA.(41)

17 - Bliss, Lisa S. (2005): "Core Stability the centerpiece of any training program" American college of sports medicine.(56)

18 - Dave Schmitz (2003): Functional Training Pyramids, New Truer High School, Kinetic Wellness Department, USA.(13-25)

19 - Dean Brittenham, Greg Brittenham (2003): Stronger ABC and Back, Human Kinetics, USA.(67)

20 - Melvin R. Ramey: Biomechanics of the long jump and triple jump, Department of Civil Engineering and Department of Physical Education University of California، Davis، California 95616، U.S.A.(202)

21 - Prentice, William (2003):"Arnheiem Principles of Athletic Training", Barns and Noble.(54)

22 - Reita, Eclaton, Mary Phg/D Wight (1997): Team handball Steps to Success Champaign, Human Kinetice.(33-44)

23 - Ron Jones (2003): Functional Training \#1: Introduction, Reebo Santana, Jose Carlos 
Univ. USA.(24)

24 - Wilf Paish(1998): The Complete Manual of Sports Science، A\&C Black Publishers LTD، London.(26)

\section{Third: Internet References}

25- $\quad$ http://www.w3c.org/tr/1999/rec-htm1401-1999/224/loose.dtd

26- http://www.iraqcad.org/forum/viewtopic.php.35

27- http://www.iraqacad.org/lip/uday.pdf 